\title{
A Novel Analytical Design Technique for a Wideband Wilkinson Power Divider Using Dual-Band Topology
}

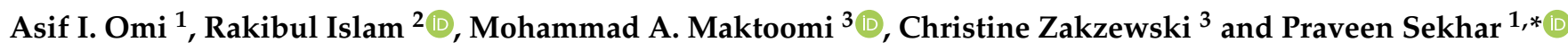 \\ 1 Department of Engineering \& Computer Science, Washington State University Vancouver, \\ Vancouver, WA 98686, USA; asif.omi@wsu.edu \\ 2 Department of Electrical \& Computer Engineering, University of Illinois at Urbana-Champaign, \\ Urbana, IL 61801, USA; rakibul2@illinois.edu \\ 3 Department of Physics \& Engineering, The University of Scranton, Scranton, PA 18510, USA; \\ mohammad.maktoomi@scranton.edu (M.A.M.); christine.zakzewski@scranton.edu (C.Z.) \\ * Correspondence: praveen.sekhar@wsu.edu
}

Citation: Omi, A.I.; Islam, R.; Maktoomi, M.A.; Zakzewski, C.; Sekhar, P. A Novel Analytical Design Technique for a Wideband Wilkinson Power Divider Using Dual-Band Topology. Sensors 2021, 21, 6330. https://doi.org/10.3390/s21196330

Academic Editor: Ángela María Coves Soler

Received: 10 September 2021 Accepted: 19 September 2021 Published: 22 September 2021

Publisher's Note: MDPI stays neutral with regard to jurisdictional claims in published maps and institutional affiliations.

Copyright: (c) 2021 by the authors. Licensee MDPI, Basel, Switzerland. This article is an open access article distributed under the terms and conditions of the Creative Commons Attribution (CC BY) license (https:/ / creativecommons.org/licenses/by/ $4.0 /)$.

\begin{abstract}
In this paper, a novel analytical design technique is presented to implement a coupledline wideband Wilkinson power divider (WPD). The configuration of the WPD is comprised of three distinct coupled-line and three isolation resistors. A comprehensive theoretical analysis is conducted to arrive at a set of completely new and rigorous design equations utilizing the dual-band behavior of commensurate transmission lines. Further, the corresponding S-parameters equations are also derived, which determine the wideband capability of the proposed WPD. To validate the proposed design concept, a prototype working at the resonance frequencies of $0.9 \mathrm{GHz}$ and $1.8 \mathrm{GHz}$ is designed and fabricated using 60 mils thick Rogers' RO4003C substrate. The measured result of the fabricated prototype exhibits an excellent input return loss $>16.4 \mathrm{~dB}$, output return loss $>15 \mathrm{~dB}$, insertion loss $<3.30 \mathrm{~dB}$ and a remarkable isolation $>22 \mathrm{~dB}$ within the band and with a $15 \mathrm{~dB}$ and 10 $\mathrm{dB}$ references provide a fractional bandwidth of $110 \%$ and $141 \%$, respectively.
\end{abstract}

Keywords: coupled-line; coupler; dual-band; S-parameter; Wilkinson power divider

\section{Introduction}

Power divider/splitter circuits are one of the essential building blocks in all modern microwave and wireless communication systems [1]. The three-port Wilkinson power divider (WPD) is considered a paragon among such passive components. WPD was first published in 1960 by Ernest J Wilkinson and used to provide electrically isolated output branches with the same phase and equal power division, with all terminated ports matched, in a very simple layout [2]. However, the presence of the intrinsically narrow bandwidth of the conventional WPD has turned out to be one of the major design challenges. A variety of modified WPD configurations have emerged over the years to cater to the needs of wideband, harmonic-suppressed, and multi-standard topologies [3-27]. Recently, the wideband WPDs have gained paramount importance in various applications such as power amplifiers [28-31], Hilbert transformer-based dual-band single sideband modulator [32,33], antenna arrays [34], phase shifters [35], and other RF front-end systems [36]. This is mainly due to the recent progress in high data-rate 5G/6G wireless systems that has refueled significant research interest in developing the next generation of wideband power dividers [37-48].

To broaden the operational bandwidth, the fundamental idea has been to incorporate a multi-section topology as proposed by Cohn [3]. Many different varieties of broadband power dividers ensued [4-12] following Cohn's idea. The conventional multi-section WPD design [2] is a fully analytical technique but only for a two-section WPD. For three and more sections, the reported technique is a table-based design and is, therefore, less computer friendly. Furthermore, among the multiple other demonstrated techniques to 
extend the bandwidth, the notable ones are those based on the stepped-impedance matching network [13], complementary conducting-strip transmission line (CCSTL) [14], port extension [15-17], substrate-integrated waveguide (SIW) [18], series/parallel RLC networks [19-22], composite right-/left-handed transmission (CRLT) lines [23], and optimized isolation network [24-27]. While CCSTL and SIW suggest alternate structure to enhance the bandwidth, on the contrary the lumped RLC networks, CRLT lines as well as the isolation network add complexity in theoretical analysis with an increase in length to serve the same purpose. Most of these works only focus on improving the bandwidth performance for either the input/output reflection parameters or the insertion loss parameter or the isolation parameter or their combinations, but not all together. In addition, for all these conventional designs for a $\mathrm{BW}=f_{2}-f_{1}$ the reflection profile appears like the one shown in Figure 1 a with $f_{0}$ being the mid-band frequency and $-\left|S_{11 m}\right|$ being the minimum return loss. Therefore, in the event of ubiquitous component/process variations, the bandwidth target is never achieved, necessitating post-design optimization.

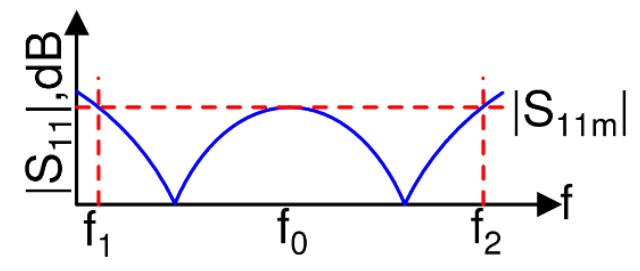

(a) The conventional approach

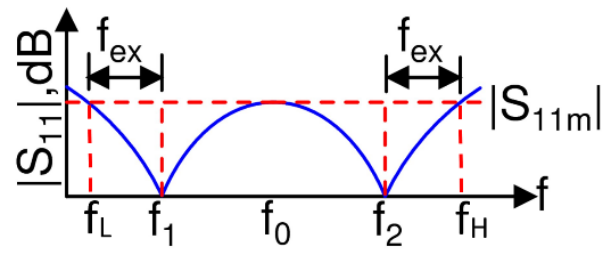

(b) Dual-band approach

Figure 1. The conventional vs. the proposed design methodologies.

In this paper, a new and rigorous analytical design methodology for the classic tri-section cascaded coupled-line-based topology is presented to maximize the bandwidth performance for all the S-parameters simultaneously. Furthermore, as depicted in Figure 1b, the proposed design methodology utilizes a dual-band design concept [37] to arrive at a wideband design. This dual-band design approach guarantees that the resonance frequencies are always located at $f_{1}$ and $f_{2}$, and therefore, the achieved bandwidth is $\mathrm{BW}=f_{H}-f_{L}=\left(f_{2}-f_{1}\right)+2 f_{e x}$, where $2 f_{e x}$ is the extra bandwidth that provides a margin for process/component variations. This approach is the usual choice for a commercial development setup, where the minimum bandwidth requirement $f_{2}-f_{1}$ will always be met, and $2 f_{e x}$ will allow flexibility to meet design goal requirements.

The remainder of this paper is organized as follows. In Section 2, the theory and design equations of the proposed WPD are developed. The derivation of the corresponding S-parameters and bandwidth performance is presented in Section 3. Then, the complete circuit of the proposed WPD along with its step-by-step design procedure is explained in Section 4 and few examples are demonstrated to support the theoretical design capability. Afterward, the fabricated prototype and its EM simulated and measured results are demonstrated in Section 5. Finally, the performance of this work is compared with some of the state-of-the-art techniques followed by a conclusion in Section 6.

\section{The Proposed Analytical Design Equations of the WPD}

A tri-section coupled-line 3- $\mathrm{dB}$ Wilkinson power divider (WPD) configuration is depicted in Figure 2. P1 denotes the input port of the WPD whereas P2 and P3 denote the two output ports. Each of the ports is terminated with a real impedance $Z_{0}$ (normally equal to $50 \Omega$ ). Further, $Z_{k e}$ and $Z_{k o}$ refer to the even and odd mode impedances of the $k$ th section coupled-line while $\theta$ refers to their electrical length with $k \in\{1,2,3\}$. As all the transmission lines are coupled, the physical space between the two arms of the divider will normally be very close, resulting in a miniaturized structure. 


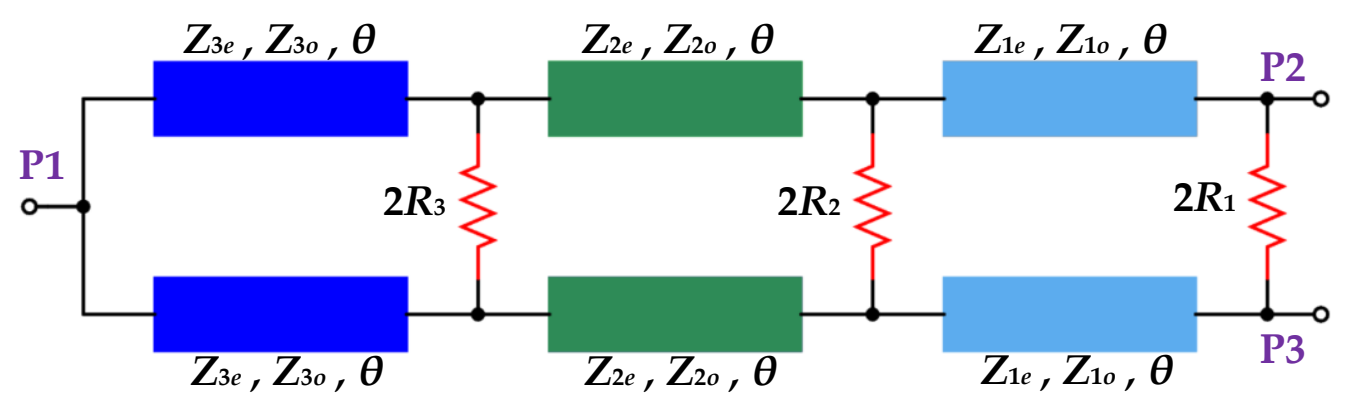

Figure 2. The tri-section coupled-line WPD.

The coupling coefficient, $C_{k}$ of the $k$ th section coupled-line is defined as [1]:

$$
C_{k}=20 \log \frac{Z_{k e}-Z_{k o}}{Z_{k e}+Z_{k o}}
$$

As explained in [37], $\theta$ at $f_{1}$ for a dual-band design is chosen as:

$$
\theta=\frac{\pi}{1+r}
$$

where $f_{1}$ and $f_{2}$ refer to the minimum band edge frequencies for the bandwidth requirement and $r=f_{2} / f_{1}$ is the band ratio.

Moreover, the three resistors $2 R_{3}, 2 R_{2}$, and $2 R_{1}$ shown in Figure 2 ensure isolation between port 2 and port 3. Since the WPD shown in Figure 2 is symmetric about a horizontal axis passing through P1, the even/odd mode analysis technique can be utilized for its analysis. The resulting equivalent circuits are depicted in Figure 3.

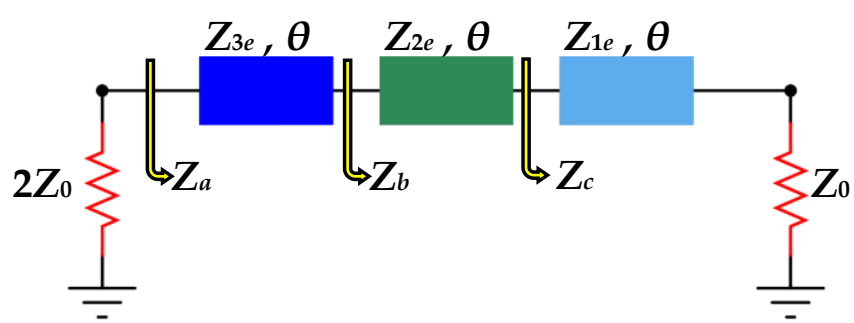

(a)

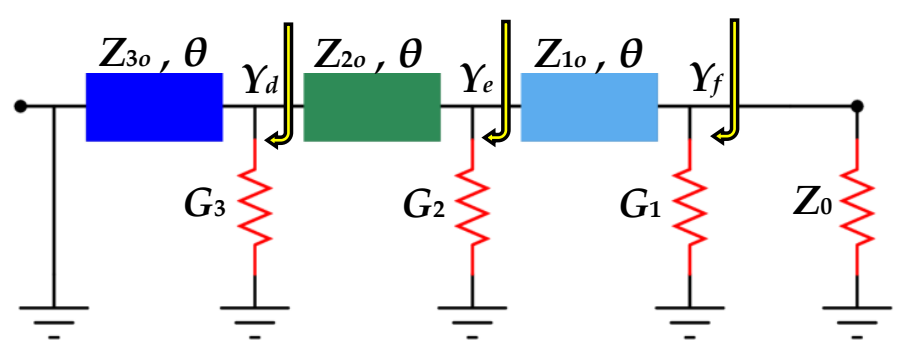

(b)

Figure 3. (a) The even-mode equivalent circuit, (b). The odd-mode equivalent circuit.

\subsection{Even-Mode Analysis}

The even-mode equivalent circuit is shown in Figure 3a. This circuit has been obtained from Figure 2 by assuming an open circuit along the axis of symmetry. As shown in the figure, the parameters $Z_{a}, Z_{b}$, and $Z_{c}$ are the input impedances looking towards the right beginning at Section 3. Using the formula of the input impedance of a transmitted transmission line [1], the following expressions can be written:

$$
\begin{aligned}
& Z_{c}=Z_{1 e} \frac{Z_{0}+j a Z_{1 e}}{Z_{1 e}+j a Z_{0}} \\
& Z_{b}=Z_{2 e} \frac{Z_{c}+j a Z_{2 e}}{Z_{2 e}+j a Z_{c}} \\
& Z_{a}=Z_{3 e} \frac{Z_{b}+j a Z_{3 e}}{Z_{3 e}+j a Z_{b}}
\end{aligned}
$$

where,

$$
a=\tan \theta
$$


Now, substituting the expressions of $Z_{c}$ into that of $Z_{b}$ and subsequently the expression of $Z_{b}$ into that of $Z_{a}$, and finally invoking $Z_{a}=2 Z_{0}$ for ideal input matching condition, the following equations are obtained [37].

$$
\begin{gathered}
Z_{2 e}^{2}+\frac{Z_{2 e}}{a Z_{3 e}}\left[a Z_{3 e}^{2}+Z_{3 e} X_{1 e}-4 a Z_{0}^{2}(1-b)\right]-\left[4 Z_{0}^{2}(1-b)+a Z_{3 e} X_{1 e}\right]=0 \\
a^{2}(1-b) Z_{3 e}^{2}+Z_{3 e}\left(b Z_{2 e}-a X_{1 e}\right)-a Z_{2 e}\left(X_{1 e}+a Z_{2 e}\right)=0
\end{gathered}
$$

where,

$$
\begin{gathered}
b=1-\frac{R_{1 e}}{2 Z_{0}} \\
R_{1 e}=\operatorname{Re}\left\{Z_{c}\right\}=\frac{Z_{0} Z_{1 e}^{2}\left(1+a^{2}\right)}{Z_{1 e}^{2}+Z_{0}^{2} a^{2}} \\
X_{1 e}=\operatorname{Im}\left\{Z_{c}\right\}=\frac{a Z_{1 e}\left(Z_{1 e}^{2}-Z_{0}^{2}\right)}{Z_{1 e}^{2}+Z_{0}^{2} a^{2}}
\end{gathered}
$$

Now eliminating $Z_{2 e}$ from (7) and (8) results in a 4th-order equation in $Z_{3 e}$ :

$$
A Z_{3 e}^{4}+B Z_{3 e}^{3}+C Z_{3 e}^{2}+D Z_{3 e}+E=0
$$

where,

$$
\begin{gathered}
A=a^{2} b(1-b) \\
B=2 a^{3}(1-b) X_{1 e} \\
C=2 b^{2} R_{1 e} Z_{0}-X_{1 e}^{2}\left(a^{4}+2 a^{2}+b\right) \\
D=-4 Z_{0} R_{1 e} X_{1 e} a^{3} \\
E=2 Z_{0} R_{1 e} a^{2}\left(X_{1 e}^{2}-2 b R_{1 e} Z_{0}\right)
\end{gathered}
$$

Subsequently, $Z_{2 e}$ is obtained from (7) and (8) as follows.

$$
Z_{2 e}=\frac{a Z_{3 e}\left[a(1-b)\left(4 Z_{0}^{2}-Z_{3 e}^{2}\right)+\left(1+a^{2}\right) X_{1 e} Z_{3 e}\right]}{\left(b+a^{2}\right) Z_{3 e}^{2}-4 Z_{0}^{2}(1-b) a^{2}}
$$

The even-mode design is completed by choosing a suitable value of $Z_{1 e}$-thus those of $R_{1 e}$ and $X_{1 e}$-and then finding $Z_{3 e}$ from (12) and $Z_{2 e}$ from (18). Out of the four roots of $Z_{3 e}$ obtained from (12) using MATLAB, only a positive real value for $Z_{3 e}$ and $Z_{2 e}$ lying between $20 \Omega$ to $120 \Omega$ is considered for modeling and implementation in the microstrip technology. The criteria for choosing $Z_{1 e}$ will be outlined later in Sections 3 and 4 .

\subsection{Odd-Mode Analysis}

The odd-mode equivalent circuit is shown in Figure 3b. This circuit has been obtained from the one shown in Figure 2 by assuming a short-circuit along the axis of symmetry. Due to the presence of shunt resistors, it is easier to work in terms of admittances, therefore, $G_{i}$ and $Y_{i o}$ are defined as $G_{i}=1 / R_{i}$ and $Y_{i o}=1 / Z_{i o}, i \in\{1,2,3\}$.

As shown in Figure $3 b$, the parameters $Y_{f}, Y_{e}, Y_{d}$ are the input admittances looking towards the left at the $i$ th section including the conductance $G_{i}=1 / R_{i}$ at that node. Applying the formula of input admittance for a terminated transmission line section [1], we have:

$$
\begin{gathered}
Y_{d}=G_{3}-j \frac{Y_{30}}{a} \\
Y_{e}=G_{2}+Y_{2 o} \frac{Y_{d}+j a Y_{2 o}}{Y_{2 o}+j a Y_{d}}
\end{gathered}
$$




$$
Y_{f}=G_{1}+Y_{1 o} \frac{Y_{e}+j a Y_{1 o}}{Y_{1 o}+j a Y_{e}}
$$

Now, substituting the expression of $Y_{d}$ into that of $Y_{e}$ and subsequently the expression of $Y_{e}$ into that of $Y_{f}$, and finally invoking $Y_{f}=1 / Z_{0}=Y_{0}$ for the ideal output matching condition, the following equations are obtained.

$$
\begin{aligned}
& P_{1} G_{2}+Q_{1} G_{3}+S_{1} G_{2} G_{3}+T_{1}=0 \\
& P_{2} G_{2}+Q_{2} G_{3}+S_{2} G_{2} G_{3}+T_{2}=0
\end{aligned}
$$

where,

$$
\begin{aligned}
& P_{1}=a\left(Y_{20}+Y_{30}\right)\left(G_{1}-Y_{0}\right) \\
& Q_{1}=a\left(Y_{1 o}+Y_{2 o}\right)\left(G_{1}-Y_{0}\right) \\
& S_{1}=a\left(Y_{10}\right) \\
& T_{1}=a Y_{10} Y_{20}\left(Y_{10}+Y_{20}\right)+Y_{10} Y_{30}\left(a Y_{1 o}-\frac{Y_{2}}{a}\right) \\
& P_{2}=Y_{1 o}\left(Y_{20}+Y_{30}\right) \\
& Q_{2}=Y_{10} Y_{2 o}-a^{2} Y_{10}{ }^{2} \\
& S_{2}=a^{2}\left(Y_{o}-G_{1}\right) \\
& T_{2}=\left(G_{1}-Y_{o}\right)\left(Y_{1 o} Y_{2 o}+Y_{2 o} Y_{3 o}+Y_{1 o} Y_{3 o}-a^{2} Y_{2 o}{ }^{2}\right)
\end{aligned}
$$

Now eliminating $G_{3}$ from (22) and (23) results in a second-order equation in $G_{2}$ :

$$
M G_{2}^{2}+N G_{2}+L=0
$$

where,

$$
\begin{gathered}
M=P_{2} S_{1}-P_{1} S_{2} \\
N=P_{2} Q_{1}-P_{1} Q_{2}+T_{2} S_{1}-T_{1} S_{2} \\
L=T_{2} Q_{1}-T_{1} Q_{2}
\end{gathered}
$$

From (32), $G_{2}$ can be found as follows:

$$
G_{2}=\frac{-N \pm \sqrt{N^{2}-4 M L}}{2 M}
$$

Putting the values of (36) in (22), $G_{3}$ can be found as follows:

$$
G_{3}=\frac{-\left(T_{1}+G_{2} P_{1}\right)}{Q_{1}+G_{2} S_{1}}
$$

Choosing suitable values of $G_{1}, Y_{10}, Y_{20}$, and $Y_{30}$, and subsequently finding the values $G_{2}$ from (36) and that of $G_{3}$ from (37) completes the WPD design process. The criteria for choosing the free variables $G_{1}, Y_{10}, Y_{20}, Y_{30}$ will be outlined later in Sections 3 and 4.

\section{The Scattering Parameters of the WPD and BW Determination}

The expression developed in Section 2 can be used to analytically design the threesection coupled-line WPD. However, due to the presence of many free variables, it is pertinent to find the expression of the S-parameters of the WPD. Due to the symmetry of the circuit shown in Figure 1, the expressions of the S-parameters for the WPD are related to the S-parameters of equivalent even-odd mode circuits as follows [16].

$$
S_{11}=S_{11 e}
$$




$$
\begin{gathered}
S_{12}=S_{21}=S_{31}=S_{13}=\frac{1}{\sqrt{2}} S_{21 e} \\
S_{22}=S_{33}=\frac{1}{2}\left(S_{22 e}+S_{22 o}\right) \\
S_{23}=S_{32}=\frac{1}{2}\left(S_{22 e}-S_{22 o}\right)
\end{gathered}
$$

From (38) and (39), it is observed that the input matching and transmission performance of the proposed power divider in Figure 1 is only determined by the even-mode parameters $S_{11 e}$ and $S_{21 e}$. However, the output matching and isolation performances are affected by both the even as well as the odd-mode parameters $S_{22 e}$ and $S_{220}$ as seen from (40) and (41).

\subsection{Expressions of Even-Mode S-Parameters}

From the even-mode circuit shown in Figure $3 a, S_{11 e}, S_{21 e}$, and $S_{22 e}$ are obtained as follows [1]:

$$
\begin{aligned}
S_{11 e}=\frac{Z_{a}-2 Z_{0}}{Z_{a}+2 Z_{0}} & =\frac{X+Y}{A_{e}+\frac{B_{e}}{Z_{0}}+2 C_{e} Z_{0}+2 D_{e}} \\
S_{21 e} & =\frac{2 \sqrt{2} S_{11 e}}{W(X+Y)} \\
S_{22 e} & =\frac{S_{11 e}(X-Y)}{(X+Y)}
\end{aligned}
$$

where, $Z_{a}$ can be calculated utilizing (3), (4), and (5) after finding $Z_{1 e}, Z_{2 e}$, and $Z_{3 e}$. Further, the parameters $W, X, Y, A_{e}, B_{e}, C_{e}$, and $D_{e}$ can be calculated from the conversion between $\mathrm{ABCD}$-parameters and S-parameters as follows [1]:

$$
\begin{gathered}
X=\frac{B_{e}}{Z_{0}}-2 C_{e} Z_{0} \\
Y=A_{e}-2 D_{e} \\
W=\left(1+a^{2}\right)^{\frac{-3}{2}} \\
A_{e}=\left[1-a^{2}\left(u+v+\frac{v}{u}\right)\right] \\
B_{e}=j a Z_{1 e}\left[1+u+v-a^{2}\left(\frac{v}{u}\right)\right] \\
C_{e}=j a \frac{1}{Z_{1 e}}\left[1+\frac{1}{u}+\frac{1}{v}-a^{2}\left(\frac{u}{v}\right)\right] \\
D_{e}=\left[1-a^{2}\left(\frac{1}{u}+\frac{1}{v}+\frac{u}{v}\right)\right] \\
u=\frac{Z_{2 e}}{Z_{1 e}} \\
v=\frac{Z_{3 e}}{Z_{1 e}}
\end{gathered}
$$

\subsection{Expression of Odd-Mode S-Parameters}

From the odd-mode circuit in Figure $3 \mathrm{~b}, S_{220}$ is obtained as follows:

$$
S_{22 o}=\frac{\left(1 / Y_{f}\right)-Z_{0}}{\left(1 / Y_{f}\right)+Z_{0}}
$$


where $Y_{f}$ can be obtained from (21) after finding $Z_{10}, Z_{20}, Z_{30}, G_{1}, G_{2}$, and $G_{3}$.

\subsection{Maximum Input Return loss $(R L)$ between $f_{1}$ and $f_{2}$}

To achieve the maximum possible BW between $f_{L}$ and $f_{H}$ (as shown in Figure 1), it is desirable to minimize the value of return loss between $f_{1}$ and $f_{2}$. To that end, using (38), (42), (45), (46), and (48)-(51) we obtain the following expression for $S_{11}$ :

$$
S_{11}=\frac{Z_{0}\left(k_{1} a^{2}-1\right)+j\left(k_{2} a-k_{3} a^{3}\right)}{Z_{0}\left(3-k_{4} a^{2}\right)+j\left(k_{5} a-k_{6} a^{3}\right)}
$$

where,

$$
\begin{gathered}
k_{1}=2\left(\frac{1}{u}+\frac{1}{v}+\frac{u}{v}\right)-\left(u+v+\frac{v}{u}\right) \\
k_{2}=Z_{1 e}(1+u+v)-\frac{2 Z_{0}^{2}}{Z_{1 e}}\left(1+\frac{1}{u}+\frac{1}{v}\right) \\
k_{3}=Z_{1 e}\left(\frac{v}{u}\right)-\frac{2 Z_{0}^{2}}{Z_{1 e}}\left(\frac{u}{v}\right) \\
k_{4}=2\left(\frac{1}{u}+\frac{1}{v}+\frac{u}{v}\right)+\left(u+v+\frac{v}{u}\right) \\
k_{5}=Z_{1 e}(1+u+v)+\frac{2 Z_{0}^{2}}{Z_{1 e}}\left(1+\frac{1}{u}+\frac{1}{v}\right) \\
k_{6}=Z_{1 e}\left(\frac{v}{u}\right)+\frac{2 Z_{0}^{2}}{Z_{1 e}}\left(\frac{u}{v}\right)
\end{gathered}
$$

Now expressing $\left|S_{11}\right|$ in $\mathrm{dB}$, (55) can be written as

$$
\left|S_{11}\right|_{d B}=10 \log \frac{Z_{0}^{2}\left(k_{1} a^{2}-1\right)^{2}+a^{2}\left(k_{2}-k_{3} a^{2}\right)^{2}}{Z_{0}^{2}\left(3-k_{4} a^{2}\right)^{2}+a^{2}\left(k_{5}-k_{6} a^{2}\right)^{2}}
$$

To find the maxima/minima of $\left|S_{11}\right| \mathrm{dB}$ between $f_{1}$ and $f_{2}$,

$$
\begin{aligned}
& \frac{d}{d a}\left|S_{11}\right|_{d B}=0 \\
& \Rightarrow c_{1}\left(a^{2}\right)^{4}+c_{2}\left(a^{2}\right)^{3}+c_{3}\left(a^{2}\right)^{2}+c_{4} a^{2}+c_{5}=0
\end{aligned}
$$

where,

$$
\begin{gathered}
c_{1}=Z_{0}^{2}\left(k_{3}^{2} k_{4}^{2}-k_{1}^{2} k_{6}^{2}\right)-2 k_{3}^{2} k_{5}^{2}+2 k_{3} k_{6}\left(2 k_{2} k_{6}-k_{3} k_{5}\right) \\
c_{2}=4 Z_{0}^{2}\left(k_{6}^{2} k_{1}-3 k_{3}^{2} k_{4}\right)+2\left(k_{3}^{2} k_{5}^{2}-k_{2}^{2} k_{6}^{2}\right) \\
c_{3}=2 Z_{0}^{4} k_{1} k_{4}\left(k_{4}-3 k_{1}\right)+Z_{0}^{2}\left(k_{1}^{2} k_{5}^{2}-k_{2}^{2} k_{4}^{2}+27 k_{3}^{2}+\right. \\
\left.12 k_{2} k_{3} k_{4}-4 k_{1} k_{5} k_{6}-3 k_{6}^{2}\right)+2 k_{5}\left(k_{2}^{2} k_{6}-k_{2} k_{3} k_{5}\right) \\
c_{4}=2 Z_{0}^{4}\left(9 k_{1}^{2}-k_{4}^{2}\right)+4 Z_{0}^{2}\left(k_{5} k_{6}-9 k_{2} k_{3}\right) \\
c_{5}=6 Z_{0}^{4}\left(k_{4}-3 k_{1}\right)+Z_{0}^{2}\left(9 k_{2}^{2}-k_{5}^{2}\right)
\end{gathered}
$$

Evaluating $c_{1}, c_{2}, c_{3}, c_{4}$, and $c_{5}$ from (64) to (68) and subsequently solving (63), we get the values of parameter $a$, which, upon substitution into (62), gives the maxima/minima of $\left|S_{11}\right|_{d B}$ between $f_{1}$ and $f_{2}$. It must be noted that earlier we defined the expression for $a$ in (6), which is a particular solution of (63) and indicates the dependence of $\left|S_{11}\right|_{d B}$ only at $f_{1}$ and $f_{2}$. In contrast, (63) yields a more general solution set of $a$ that provides information about all the maxima/minima between $f_{1}$ and $f_{2}$ as the even mode impedances $\left(Z_{1 e}, Z_{2 e}\right.$, $Z_{3 e}$ ) vary.

Some Special Cases for Input RL

The following important points can be observed regarding the behavior of $\left|S_{11}\right|_{d B}$. 
(i) Using (55) and (63), the common realizable solutions of $a$, irrespective of the value of $r$, can be found as:

$$
a^{2}=\frac{k_{2}}{k_{3}}=\frac{1}{k_{1}}=\tan ^{2} \theta
$$

These values of $a$ correspond to the values of $\left|S_{11}\right|_{d B}$ at $f_{1}$ and $f_{2}$ where we will always get two minima, which is also evident from (6) owing to the dual-band principle. Now applying any suitable numerical analysis tool, we can calculate two other real values of $a\left(a_{m 1}\right.$ and $\left.a_{m 2}\right)$. These values of $a$ indicate two maxima of $\left|S_{11}\right|_{d B}$ at $f_{m 1}$ and $f_{m 2}$ where $f_{1}<f_{m 1}<f_{c}$ and $f_{c}<f_{m 2}<f_{2}$ and the center frequency, $f_{c}=0.5\left(f_{1}+\right.$ $\left.f_{2}\right)=0.5\left(f_{L}+f_{H}\right)$. These frequency levels are graphically defined in Figure 4 .

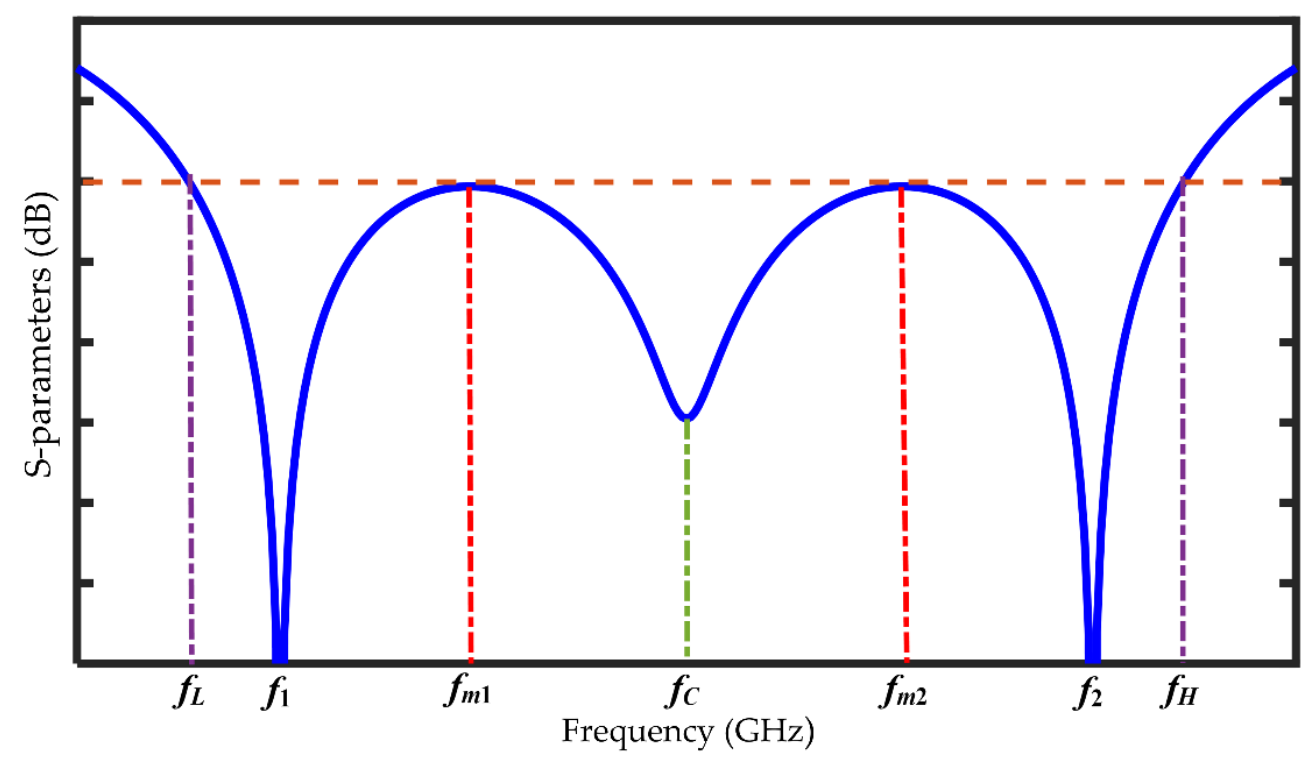

Figure 4. Specific frequency terms in S-Parameters.

Furthermore, since $\theta \propto f$, the following equations can be derived with the help of (2) for which $\left|S_{11}\right|_{d B}$ becomes the maximum.

$$
\begin{gathered}
f_{m 1}=\frac{f_{1}(1+r)}{\pi} \tan ^{-1} a_{m 1} \\
f_{m 2}=f_{1}(1+r)-f_{m 1}
\end{gathered}
$$

Some examples are shown in Table 1 where different solutions of $a$ from (63) have

\begin{tabular}{|c|c|c|c|c|c|}
\hline \multirow{2}{*}{ Band Ratio, $r$} & \multicolumn{3}{|c|}{$\mathrm{Z}_{k e}$ Values, $k \in\{1,2,3\}$} & \multirow{2}{*}{ Solution of $a$} & \multirow{2}{*}{$\begin{array}{l}\text { Remarks on }\left|S_{11}\right|_{d B} \\
\text { from the Value of } a\end{array}$} \\
\hline & $Z_{1 e}(\Omega)$ & $Z_{2 e}(\Omega)$ & $Z_{3 e}(\Omega)$ & & \\
\hline \multirow{2}{*}{2} & \multirow{2}{*}{56.1520} & \multirow{2}{*}{70.7107} & \multirow{2}{*}{89.0442} & $\pm \sqrt{3}$ & Minima at $f_{1} \& f_{2}$ \\
\hline & & & & $\pm \sqrt{11}$ & Maxima at $f_{m 1} \& f_{m 2}$ \\
\hline \multirow{2}{*}{3} & \multirow{2}{*}{59.5380} & \multirow{2}{*}{70.7107} & \multirow{2}{*}{83.9807} & \pm 1 & Minima at $f_{1} \& f_{2}$ \\
\hline & & & & $\pm \sqrt{5}$ & Maxima at $f_{m 1} \& f_{m 2}$ \\
\hline \multirow{2}{*}{4} & \multirow{2}{*}{64.3670} & \multirow{2}{*}{70.7106} & \multirow{2}{*}{77.6800} & $\pm \sqrt{5-2 \sqrt{5}}$ & Minima at $f_{1} \& f_{2}$ \\
\hline & & & & $\pm 8 \sqrt{7} / 5 \sqrt{5}$ & Maxima at $f_{m 1} \& f_{m 2}$ \\
\hline
\end{tabular}
been tabulated.

Table 1. Calculated real values of $a$ from (63). 
(ii) From (62), it can be further deduced that, for the minimum band-limited region $\left(f_{1}<f<f_{2}\right)$, we have the following cases.

$$
\text { Case }-1: \quad \frac{k_{3}}{k_{6}} \geq\left|S_{11}(f)\right|
$$

For this case, we can obtain two minima at $f_{1}, f_{2}$, and one maximum at $f_{c}$. Thus, the achievable BW can be found at the $\left|S_{11}\left(f_{c}\right)\right|_{d B}$ level which is also visible from Figure $5\left(Z_{1 e}=53 \Omega\right.$ and $54 \Omega$ as examples where $\left|S_{11}\left(f_{c}\right)\right|=-25 \mathrm{~dB}$ and $-28 \mathrm{~dB}$, respectively).

$$
\text { Case }-2: \quad \frac{k_{3}}{k_{6}}<\left|S_{11}(f)\right|
$$

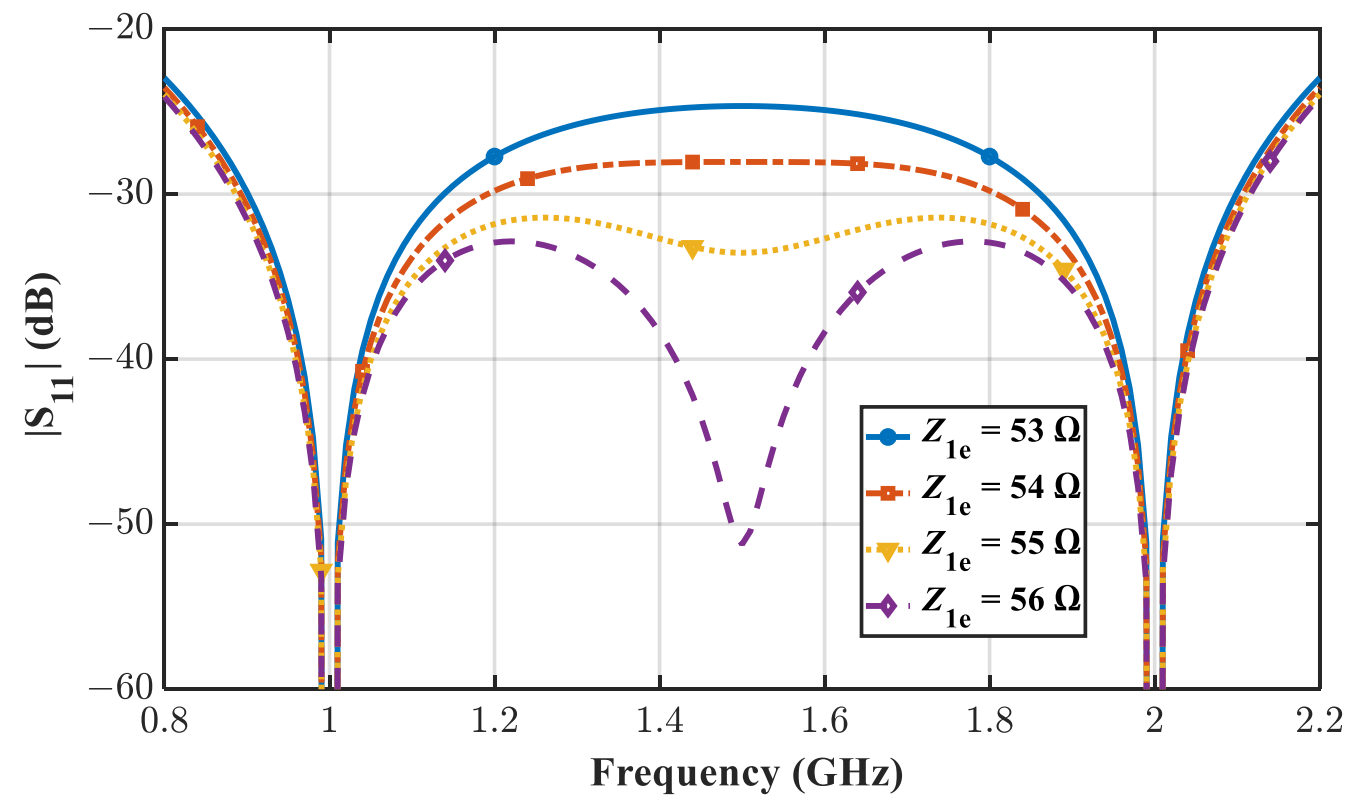

Figure 5. The behavior of $\left|S_{11}\right|$ between $f_{1}$ and $f_{2}$ for different $Z_{1 e}$ values.

For this case, we can obtain two minima at $f_{1}, f_{2}$, and two equal maxima at $f_{\mathrm{m} 1}, f_{m 2}$. Thus, the achievable BW can be found at the $\left|S_{11}\left(f_{m 1}\right)\right|_{d B}$ level which is also visible from Figure $5\left(Z_{1 e}=55 \Omega\right.$ as an example where $\left.\left|S_{11}\left(f_{m 1}\right)\right|=-31.5 \mathrm{~dB}\right)$.

$$
\text { Case }-3: \quad k_{3}<<k_{6} \& k_{3} \approx 0
$$

For the above case, we will get the minimum possible value at $f_{c}$, and this can be visualized from Figure 5 ( $Z_{1 e}=56 \Omega$ as an example). Also in this case, we will get three minima at $f_{1}, f_{c}$ and $f_{2}$, and two equal maxima at $f_{m 1}$ and $f_{m 2}$. This is also the point beyond which the maxima of $S_{11}$ cannot be lowered further by choosing any value of $Z_{1 e}, Z_{2 e}$, or $Z_{3 e}$. So, it will give the best possible $B W$ with the lowest possible $\left|S_{11}\right|_{d B}$ and the achievable BW can be found at the $\left|S_{11}\left(f_{m 1}\right)\right|_{d B}$ level where $\left|S_{11}\left(f_{m 1}\right)\right|=-33 \mathrm{~dB}$ as seen for $Z_{1 e}=56 \Omega$. Hence, from the value of $k_{3} / k_{6}$, we can decide which design parameters to choose to arrive at either of the above three cases. In a special case when $k_{3}=0$, it can be inferred from (55) that

$$
Z_{3 e} Z_{1 e}=\sqrt{2} Z_{0} Z_{2 e}
$$

Consequently, choosing $Z_{2 e}=\sqrt{2} Z_{0}$ as a particular solution of (18) and using (75), we conclude the following.

$$
Z_{2 e}=\sqrt{Z_{3 e} Z_{1 e}}
$$


Thus, after finding $Z_{1 e}$ that ensures $S_{11}=0$, Equation (76) can be used to find $Z_{3 e}$ which gives the best possible maxima of $S_{11}$ between $f_{1}$ and $f_{2}$. This equation will not be applicable unless the best possible maxima of $S_{11}$ is targeted.

(iii) Based on the variation of maxima of $S_{11}$ versus $Z_{1 e}$ shown in Figure 6, it is apparent that the higher bandwidth level can be achieved from the lower values of $r$. In fact, for $r=5$, it is not possible to achieve $10 \mathrm{~dB}$ return loss as depicted in Figure 6. Further, the best possible maxima can be achieved for a certain value of $Z_{1 e}$. From that value of $Z_{1 e}$ shown in Figure 6, we can calculate $Z_{2 e}$ and $Z_{3 e}$ from (18) and (12) respectively. It can be verified that these values of $Z_{1 e}, Z_{2 e}$, and $Z_{3 e}$ also satisfy (76).

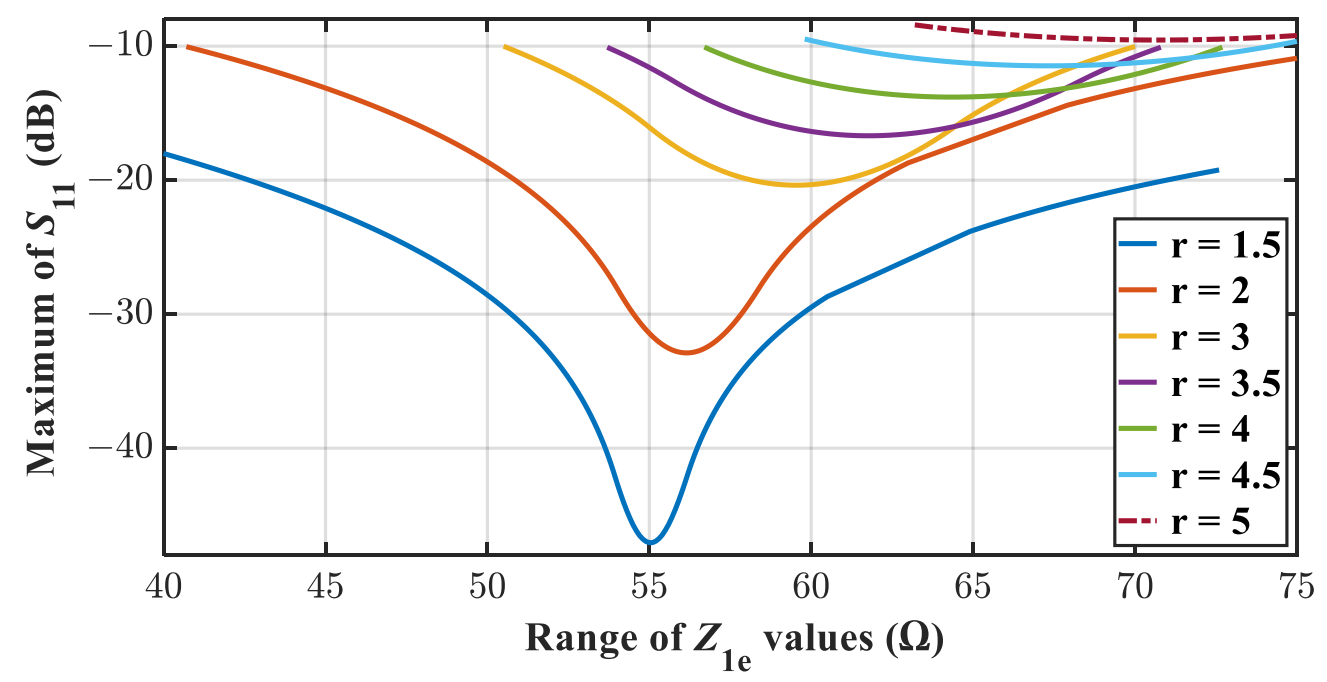

Figure 6. Variation of Maxima values of $\left|S_{11}\left(f_{1}<f<f_{2}\right)\right|$ with $Z_{1 e}$.

\subsection{Maximum Output Return Loss (RL) and Isolation between $f_{1}$ and $f_{2}$}

A similar procedure is also followed to minimize $\left|S_{22}\right|_{d B}$ and $\left|S_{23}\right|_{d B}$ between $f_{1}$ and $f_{2}$. Since there are more free variables involved compared with $\left|S_{11}\right|_{d B}$ case, one can easily perform this analysis directly in MATLAB with the help of (40), (41), (44) and (54).

\section{The Proposed Design Methodology}

To be physically realizable, coupled-line microstrip technology must have a certain specific value of coupling coefficient. We consider $C_{d}$ to be the limit of the coupling coefficient such that the actual coupling coefficient of each coupled-line section $\left|C_{k}\right|<\left|C_{d}\right|$. In addition, $S_{d}$ is the desired $S$-parameter value in $\mathrm{dB}$ to ensure the bandwidth requirement for wideband performance such that $\left(\left|S_{11}\right|_{d B(\max )},\left|S_{22}\right|_{d B(\max )}\right.$ and $\left.\left|S_{23}\right|_{d B(\max )}\right)<S_{d}$ between $f_{1}$ and $f_{2}$. With these limits set, Figure 7 depicts the flowchart for the proposed analytical design methodology to find $R_{k}, Z_{k e}$ and $Z_{k o}$ values $(k=1,2,3)$ that will ensure a wideband profile.

Following the above design methodology, some design examples for $r=1.5,2,3,3.5$, 4 , and 4.5 are shown in Table 2. The ideal S-parameters corresponding to $r=1.5,3$, and 4.5 are plotted in Figure $8 \mathrm{a}-\mathrm{c}$.

We can observe the wideband performance of the proposed WPD from the graphical representations of the ideal S-parameters. From Figure $8 \mathrm{a}-\mathrm{c}$, it is inferred that with the increased value of $r$, the wideband performance deteriorates. Specifically, it is apparent that when $r=4.5$, the return loss and isolation just touch the $-10 \mathrm{~dB}$ level between $f_{1}$ and $f_{2}$ while resulting in a transmission ripple of less than $0.4 \mathrm{~dB}$. Thus, it is theoretically possible to utilize the proposed design methodology to design the wideband WPD for $r<4.5$. 


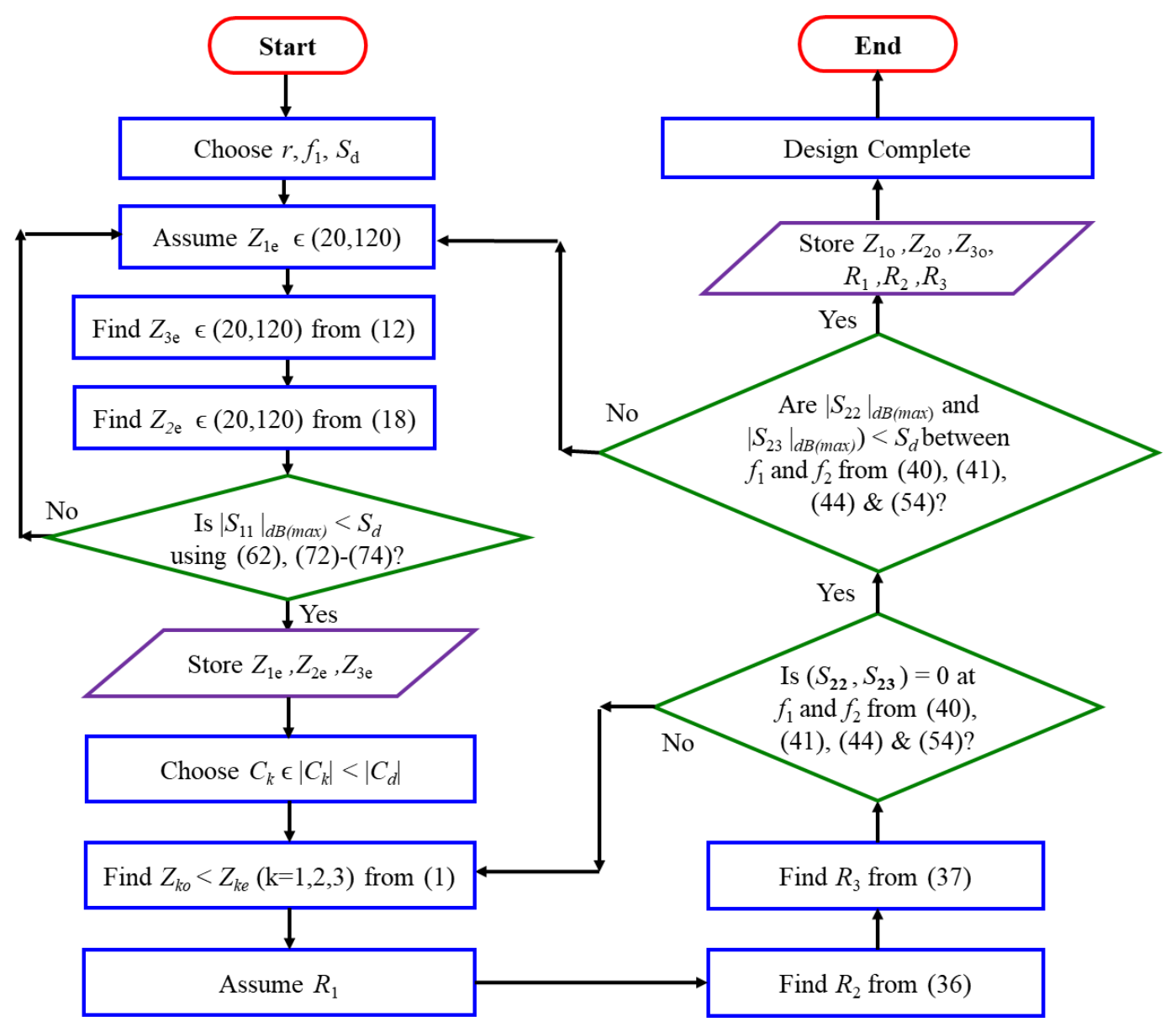

Figure 7. Flowchart of design steps.

Table 2. Circuit Parameters with the variation of $r$.

\begin{tabular}{|c|c|c|c|c|c|c|c|c|c|}
\hline$r$ & $Z_{1 e}(\Omega)$ & $Z_{1 o}(\Omega)$ & $Z_{2 e}(\Omega)$ & $Z_{2 o}(\Omega)$ & $Z_{3 e}(\Omega)$ & $Z_{3 o}(\Omega)$ & $R_{1}(\Omega)$ & $R_{2}(\Omega)$ & $R_{3}(\Omega)$ \\
\hline 1.5 & 60.00 & 37.00 & 81.26 & 42.00 & 99.04 & 50.00 & 929.00 & 31.26 & 5.01 \\
\hline 2 & 58.30 & 34.80 & 73.38 & 40.00 & 92.45 & 48.00 & 500.00 & 34.52 & 5.00 \\
\hline 3 & 59.00 & 36.00 & 70.72 & 37.00 & 83.22 & 41.00 & 910.00 & 84.20 & 23.45 \\
\hline 3.5 & 60.00 & 36.00 & 71.45 & 38.00 & 78.64 & 44.00 & 1000.00 & 81.60 & 31.15 \\
\hline 4 & 63.00 & 35.00 & 71.66 & 42.00 & 76.04 & 43.00 & 355.00 & 76.25 & 37.42 \\
\hline 4.5 & 64.50 & 34.00 & 73.26 & 40.00 & 71.17 & 41.00 & 151.00 & 109.49 & 39.42 \\
\hline
\end{tabular}

Now, from the examples considered in Table 2 and the simulation results shown in Figure $8 \mathrm{a}-\mathrm{c}$, we can easily deduce the cases listed in Table 3 and the corresponding plot depicted in Figure 8d. They reveal the wideband operability for $r<4.5$ and variation of $\%$ FBW, respectively, at different $\mathrm{dB}$ levels. We can also assess the associated \% FBW for any

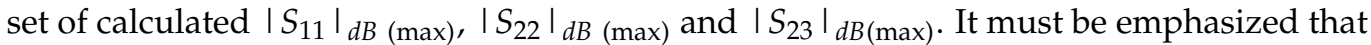
$r=f_{2} / f_{1}$ is the frequency ratio that is used only during the design process, since the design process utilizes the dual-band concept. Whereas, the actual bandwidth is determined by attainable band ratio $r_{u}=f_{\mathrm{H}} / f_{\mathrm{L}}$, as depicted in Figure $1 \mathrm{~b}$. For instance, as illustrated in Table 3, for $r=3$ we have the resonance frequencies at $1 \mathrm{GHz}$ and $3 \mathrm{GHz}$ with the attainable band ratio of 4.00 to 6.70 from $19 \mathrm{~dB}$ to $10 \mathrm{~dB}$ level (minimum of return loss and isolation) and $3.05 \mathrm{~dB}$ to $3.21 \mathrm{~dB}$ level (maximum insertion loss [1]), respectively. Since the operability in the wideband region is entirely based on the concept of the dual-band technique, it is also observed from Figure $8 \mathrm{~d}$ that our proposed WPD can be designed theoretically with 
$r_{u}$ in the range of 1-8.2. Furthermore, it is observed that we can even theoretically achieve a maximum $157 \%$ fractional BW from this newly designed WPD.

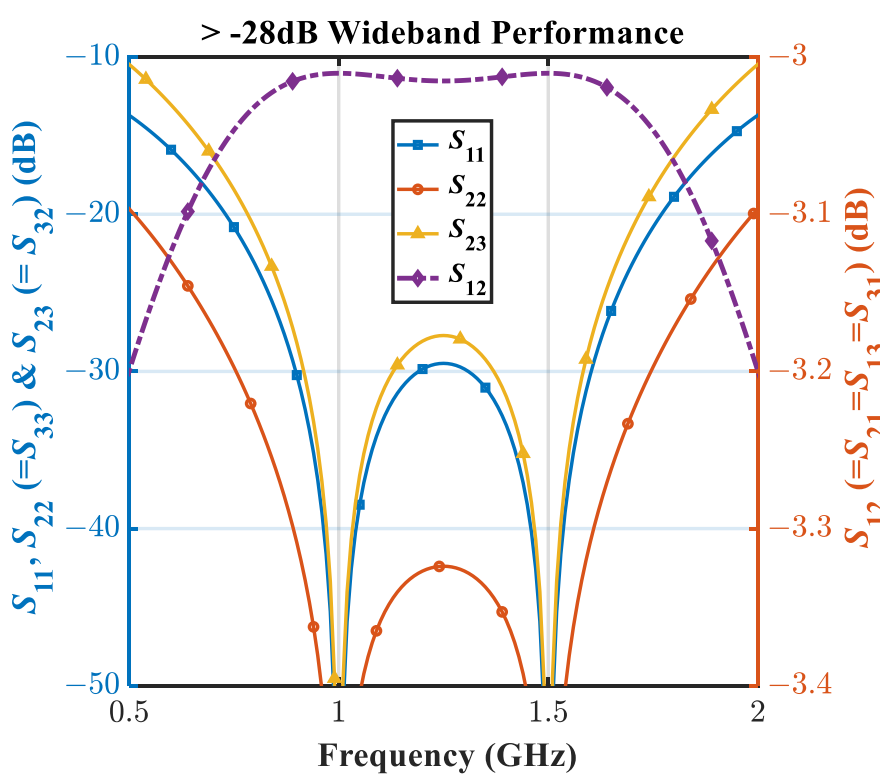

(a) Ideal S-parameters for $r=1.5$

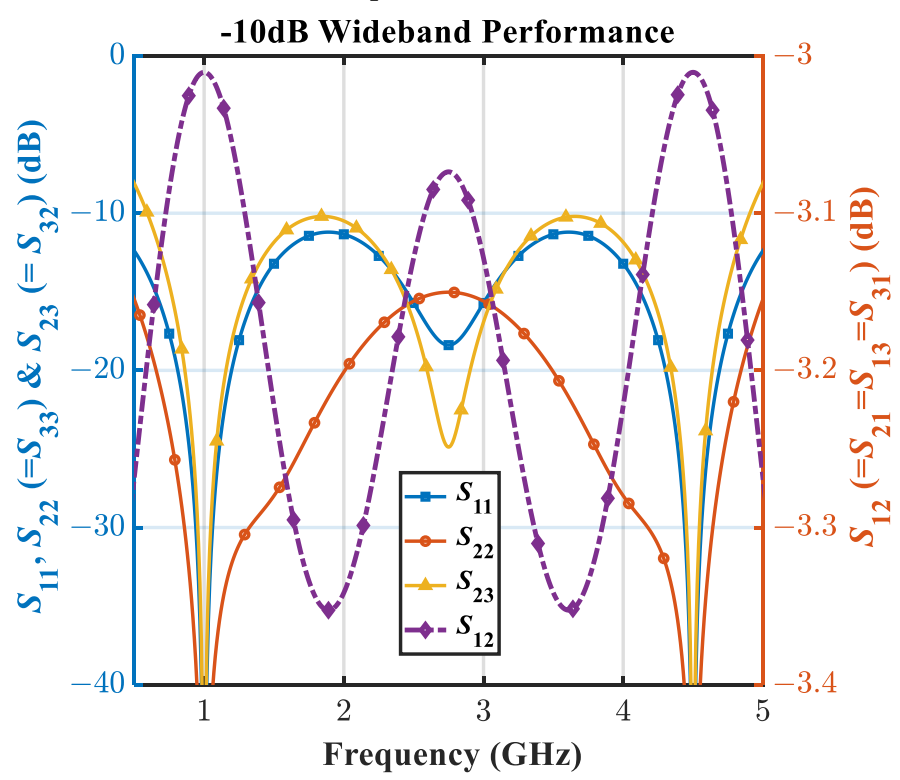

(c) Ideal S-parameters for $\mathrm{r}=4.5$

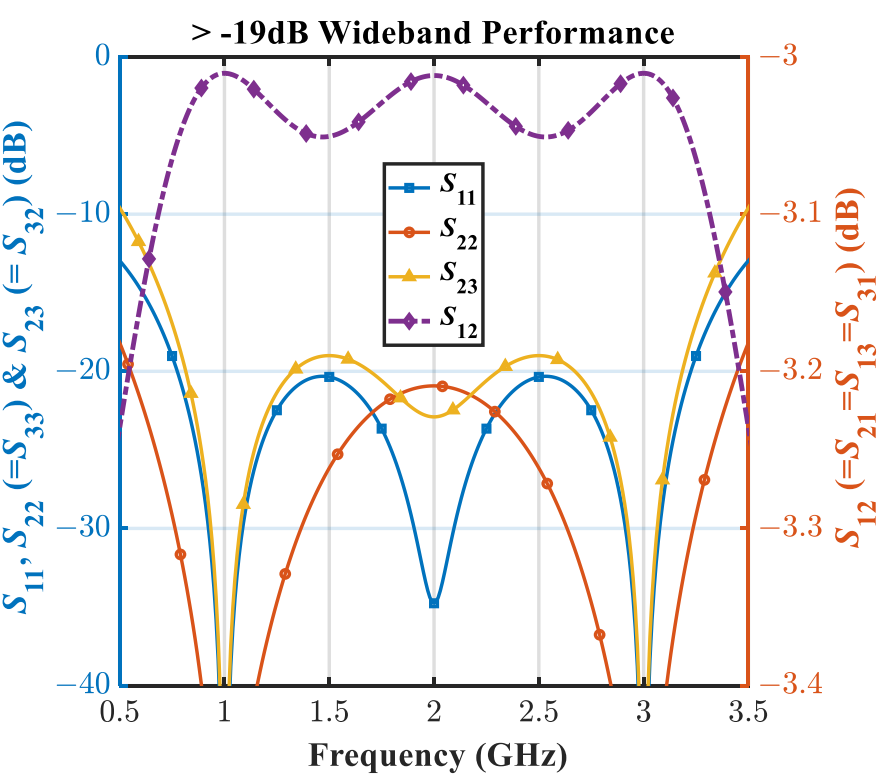

(b) Ideal S-parameters for $r=3.0$

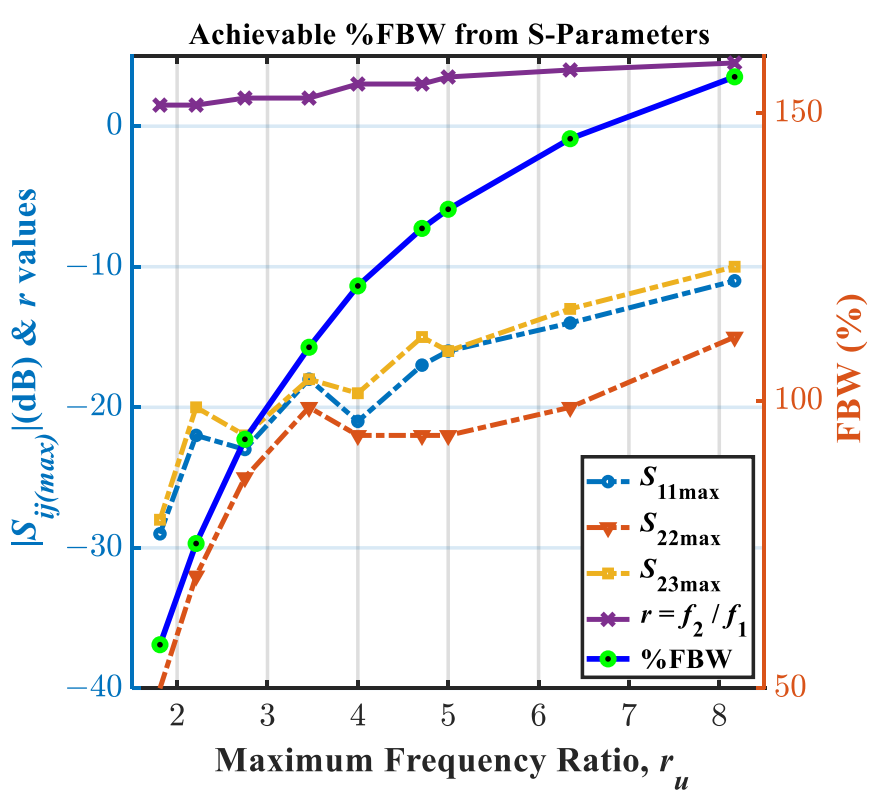

(d) Variation of Maximum S-parameter Values

Figure 8. Ideal S-parameters with the variation of $r, r_{u}$, and \%FBW.

It is apparent that for $r>4.5$, the isolation becomes lesser than $10 \mathrm{~dB}$ between $f_{1}$ and $f_{2}$, and therefore, the proposed WPD exhibits only the dual-band performance. 
Table 3. Limitation on Wideband Performance.

\begin{tabular}{|c|c|c|c|c|c|}
\hline $\begin{array}{c}\text { Minimum } \\
\text { Band Ratio, } \\
\quad R\end{array}$ & $\begin{array}{l}\text { Minimum of } \\
\text { Return loss \& } \\
\text { Isolation } \\
\text { (dB) }\end{array}$ & $\begin{array}{l}\text { Maximum } \\
\text { Insertion loss } \\
\text { (dB) }\end{array}$ & $\begin{array}{c}\text { Operating } \\
\text { Band Range, } \\
f_{L} \text { to } f_{H} \\
(\mathrm{GHz})\end{array}$ & $\begin{array}{c}\text { Extra BW, } \\
f_{e x} \\
(\mathrm{GHz})\end{array}$ & $\begin{array}{c}\text { Attainable Band } \\
\text { Ratio, } \\
r_{u}\end{array}$ \\
\hline \multirow{2}{*}{1.50} & 28 & 3.01 & $0.89-1.61$ & 0.11 & 1.81 \\
\hline & 10 & 3.20 & $0.48-2.02$ & 0.52 & 4.21 \\
\hline \multirow{2}{*}{2.00} & 20 & 3.02 & $0.80-2.20$ & 0.20 & 2.75 \\
\hline & 10 & 3.20 & $0.50-2.50$ & 0.50 & 5.00 \\
\hline \multirow{2}{*}{3.00} & 19 & 3.05 & $0.80-3.20$ & 0.20 & 4.00 \\
\hline & 10 & 3.21 & $0.52-3.48$ & 0.48 & 6.69 \\
\hline \multirow{2}{*}{3.50} & 16 & 3.11 & $0.75-3.75$ & 0.25 & 6.35 \\
\hline & 10 & 3.22 & $0.55-3.95$ & 0.45 & 7.77 \\
\hline \multirow{2}{*}{4.00} & 13 & 3.20 & $0.68-4.32$ & 0.32 & 5.00 \\
\hline & 10 & 3.22 & $0.57-4.43$ & 0.43 & 7.18 \\
\hline 4.50 & 10 & 3.35 & $0.60-4.90$ & 0.40 & 8.17 \\
\hline
\end{tabular}

\section{The Fabricated Prototype and Measurement Results}

The proposed analytical design methodology is used to design a wideband WPD with $S_{d}<-20 \mathrm{~dB}$ and $C_{d}=-12 \mathrm{~dB}$ as a demonstration. If the resonance frequencies are chosen as $f_{1}=0.9 \mathrm{GHz}$ and $f_{2}=1.8 \mathrm{GHz}$, then the calculated ideal design parameters using MATLAB are found to be as: $Z_{1 e}=54.00 \Omega, Z_{2 e}=68.04 \Omega, Z_{3 e}=85.63 \Omega, Z_{10}=35.00 \Omega$, $Z_{20}=40.00 \Omega, Z_{3 o}=45.00 \Omega, R_{1}=599.00 \Omega, R_{2}=37.87 \Omega$, and $R_{3}=8.05 \Omega$.

Based on the analytical design, these values are subsequently used to implement and optimize the WPD in microstrip technology using the ADS design environment. The optimized (to tackle junction discontinuities) physical dimensions of the designed prototype are listed in Table 4. Based on these dimensions, the designed WPD electromagnetic (EM) model is shown in Figure 9 whereas the fabricated prototype is depicted in Figure 10. The Rogers' RO4003C laminate is used with the following parameters: dielectric constant, $\epsilon_{\mathrm{r}}=3.55$, substrate height $=1.524 \mathrm{~mm}$, thickness $=35 \mu \mathrm{m}$ and loss tangent, $\tan \delta=0.002$. The final resistors for this prototype WPD are: $2 R_{1}=634 \Omega, 2 R_{2}=95.3 \Omega$, and $2 R_{3}=24.9 \Omega$ which correspond to commercially available values.

The prototype is measured using the Tektronix TTR506A vector network analyzer (VNA) with a full two-port SOLT calibration as shown in Figure 11. The EM simulated and the measured results in the range of $0.3 \mathrm{GHz}-2.7 \mathrm{GHz}$ are compared in Figures 12 and 13.

Table 4. Physical Dimension of the Coupled T-lines.

\begin{tabular}{cccc}
\hline & 3rd Line $(\mathbf{n}=\mathbf{3})$ & 2nd Line $(\mathbf{n}=\mathbf{2})$ & 1st Line $(\mathbf{n}=\mathbf{1})$ \\
\hline $\mathrm{W}_{\mathrm{n}}($ in $\mathrm{mm})$ & 1.918 & 2.823 & 3.987 \\
\hline $\mathrm{S}_{\mathrm{n}}($ in $\mathrm{mm})$ & 0.854 & 0.919 & 0.999 \\
\hline $\mathrm{L}_{\mathrm{n}}($ in $\mathrm{mm})$ & 29.66 & 33.62 & 33.82 \\
\hline
\end{tabular}




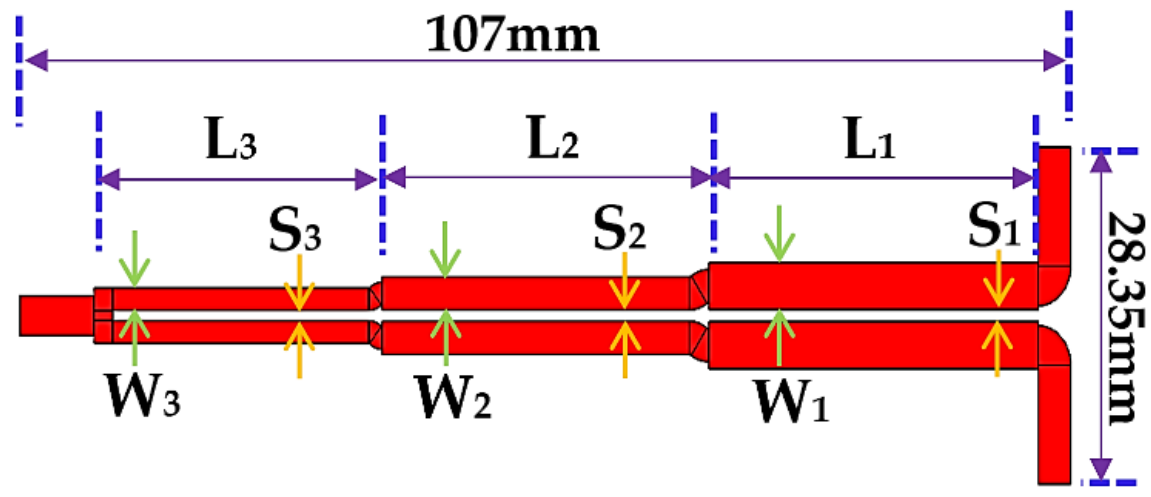

Figure 9. WPD EM modeling using ADS momentum.

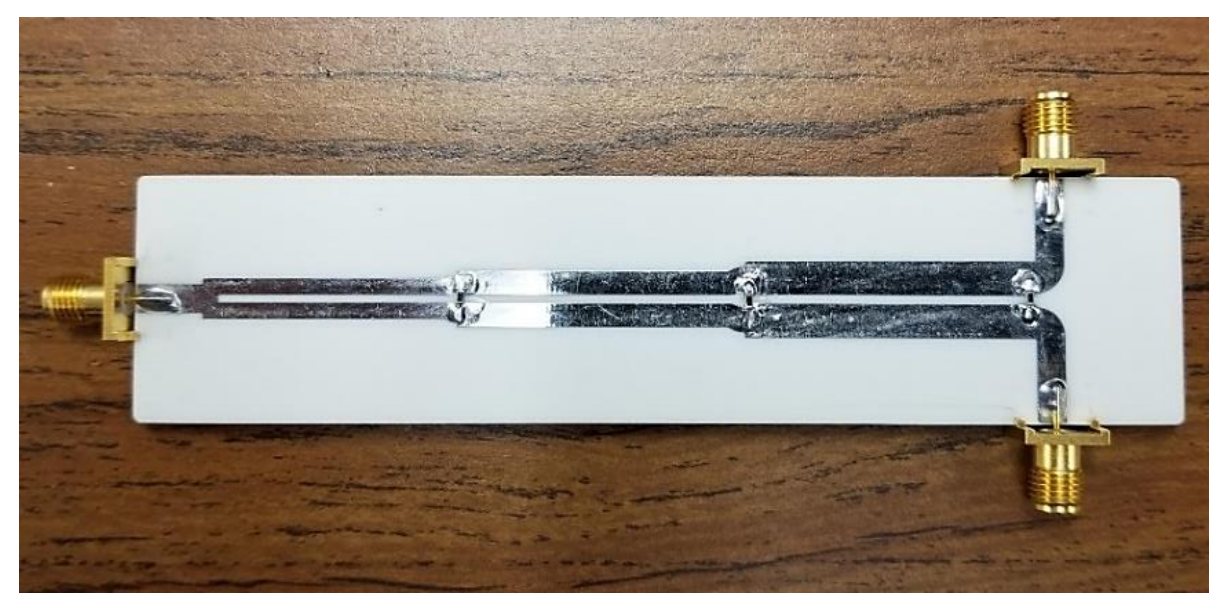

Figure 10. The fabricated prototype of the WPD.

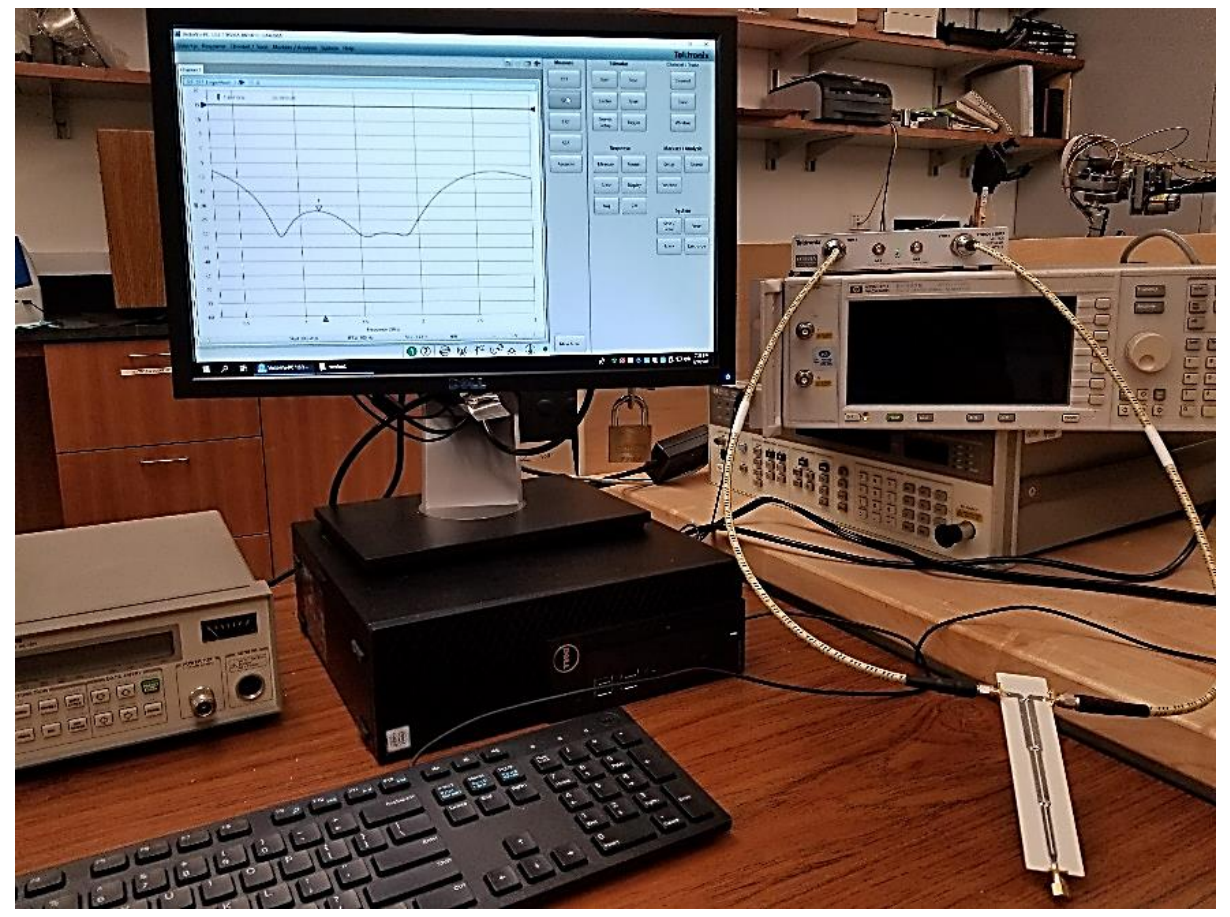

Figure 11. The measurement of the fabricated prototype using the Tektronix VNA. 


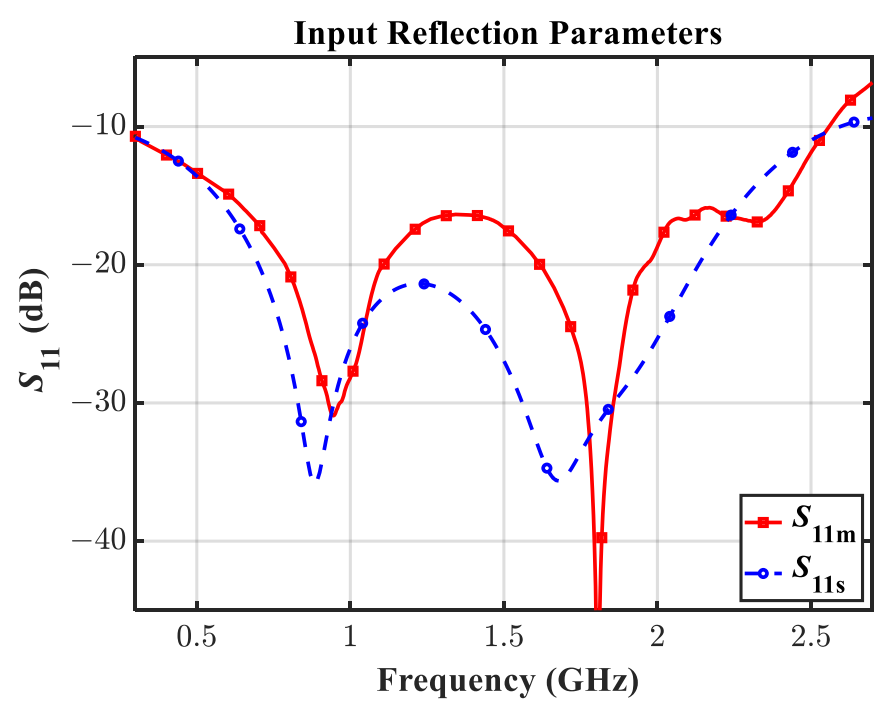

(a) Comparison of Input Reflection Parameters

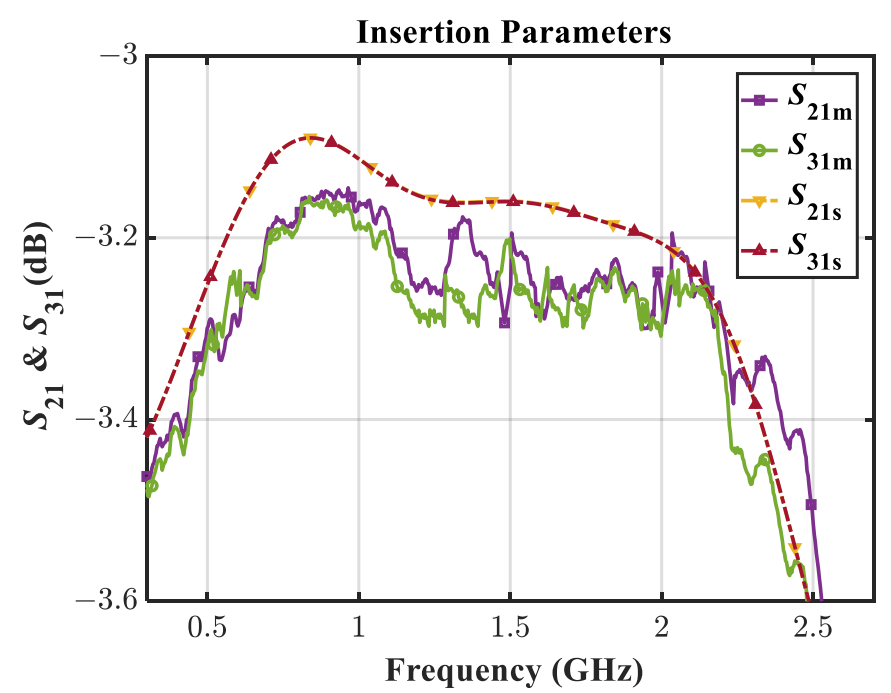

(c) Comparison of Insertion Parameters

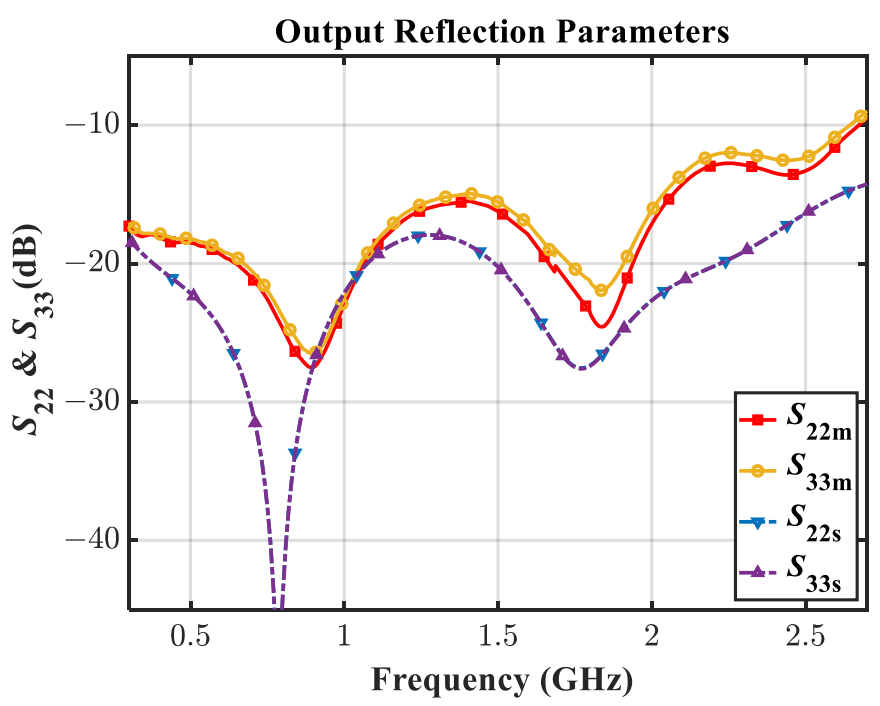

(b) Comparison of Output Reflection Parameters

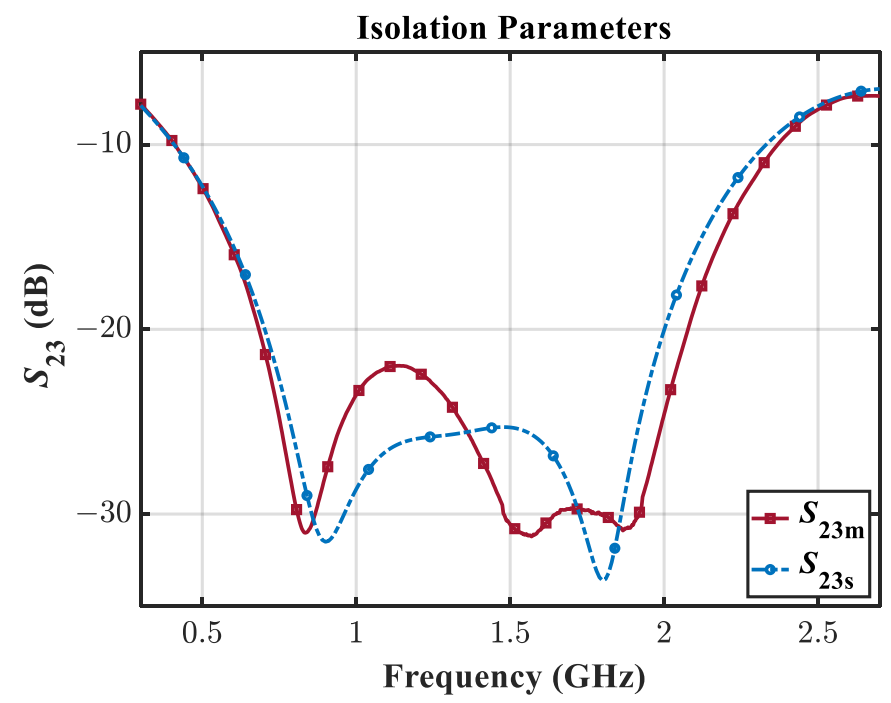

(d) Comparison of Isolation Parameters

Figure 12. The EM simulated (subscript s) vs. the measured (subscript m) magnitudes of S-parameters.

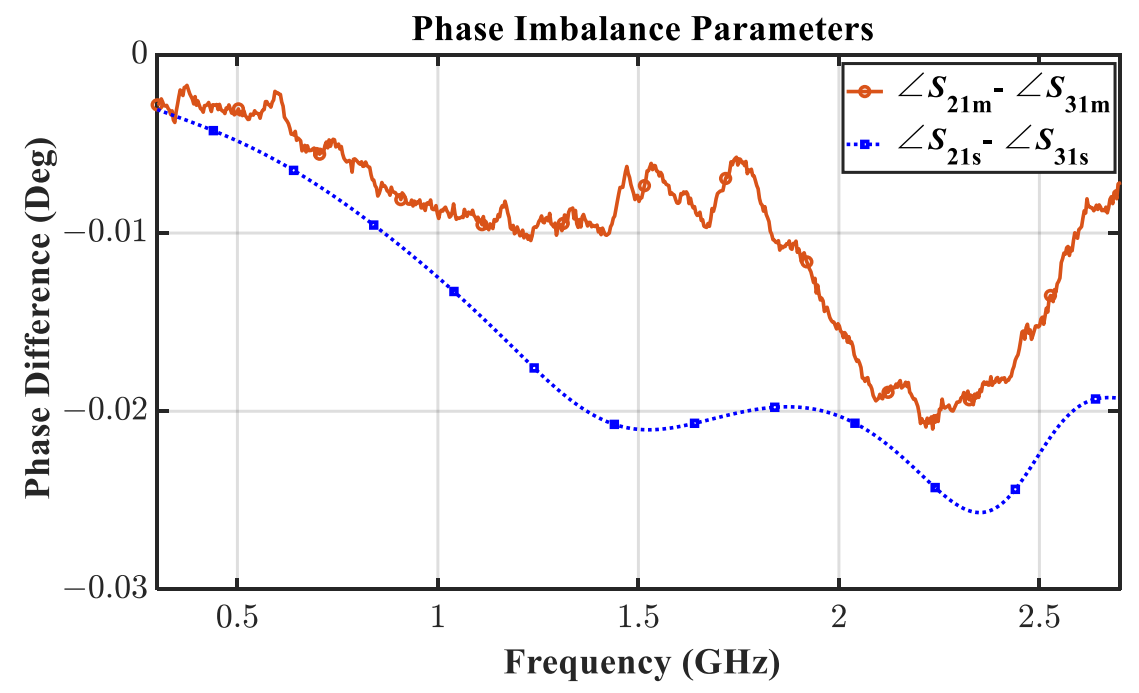

Figure 13. Simulated (subscript s) vs. measured (subscript $\mathrm{m}$ ) phase imbalance between output ports. 
It is apparent from Figure 12a,b that the designed prototype has excellent reflection parameters maintaining an input return loss greater than $16.4 \mathrm{~dB}$ and an output return loss greater than $15 \mathrm{~dB}$ throughout the band from $0.595 \mathrm{GHz}$ to $2.05 \mathrm{GHz}$. Besides, the transmission parameters are also found to demonstrate decent performance in Figure $12 \mathrm{c}$ ensuring an insertion loss of lesser than $3.30 \mathrm{~dB}$, not far from the ideal $3 \mathrm{~dB}$ value in the aforesaid band. Moreover, as shown in Figures $12 \mathrm{~d}$ and 13, the measured isolation and phase imbalance of $22 \mathrm{~dB}$ (minimum) and value of 0.02 degrees (maximum), respectively, are remarkable. From the aforesaid band, the measured \% FBW is $110 \%$ considering the $-15 \mathrm{~dB}$ reference line whereas it becomes $141 \%$ considering a $-10 \mathrm{~dB}$ reference level from $0.41 \mathrm{GHz}$ to $2.37 \mathrm{GHz}$, which is outstanding.

Though there is a slight mismatch observed between the EM simulated and the measured values, which normally occurs in any high-frequency design, possibly it is mostly due to the Panasonic isolation resistor's non-idealities at high frequencies. Unfortunately, the model of these resistors is not available, so it was not possible to include their impact in the simulation. Nevertheless, the measured results show the outstanding performance of the WPD design which meets or exceeds all the goals that a practical WPD will require during deployment in the field.

Although the main advantage of the proposed design is its fully analytical and computer-friendly design methodology, to highlight the novelty of this work further, a comparison table is presented in Table 5 where some recent state-of-the-art works have been listed. It is conspicuous from the Table that the proposed WPD proves to be the best fit in terms of fulfilling the desired values of all the S-parameters in the wideband zone and maximizing the \% FBW at the same time compared to all these previous works.

Table 5. Comparison of performance among this WPD and some other recent works.

\begin{tabular}{|c|c|c|c|c|c|c|c|c|}
\hline Reference & Techniques/Topology & $\begin{array}{c}\text { Band } \\
\text { Ratio } \\
\left(r_{u}=f_{H} / f_{L}\right)\end{array}$ & $\begin{array}{l}\text { Min. } \\
\text { Input } \\
\text { RL } \\
\text { (dB) }\end{array}$ & $\begin{array}{l}\text { Min. } \\
\text { Output } \\
\text { RL } \\
\text { (dB) }\end{array}$ & $\begin{array}{l}\text { Min. } \\
\text { Isolation } \\
\text { level } \\
\text { (dB) }\end{array}$ & $\begin{array}{l}\text { Max. } \\
\text { Insertion } \\
\text { level } \\
\text { (dB) }\end{array}$ & $\begin{array}{c}\text { Max. Phase } \\
\text { Imbalance } \\
\text { of Outport } \\
\text { Ports } \\
\text { (Degree) }\end{array}$ & $\begin{array}{c}\text { FBW } \\
(\%)\end{array}$ \\
\hline$[24]$ & RLCT Isolation network & 3.55 & 10 & 10 & 20 & 4.00 & - & 112.00 \\
\hline [25] & Frequency-selecting coupling structure & 2.13 & 20 & - & 12 & 3.40 & 4.00 & 62.07 \\
\hline [26] & Parallel coupled filters & 1.66 & 15 & 14 & 22 & 4.00 & - & 49.50 \\
\hline$[27]$ & $\begin{array}{l}\text { Single section optimized isolation } \\
\text { network }\end{array}$ & 2.20 & 19 & 20 & 19 & 3.20 & - & 75.00 \\
\hline$[35]$ & $\begin{array}{l}\text { Two open-circuited stubs and three } \\
\text { coupled lines }\end{array}$ & 1.90 & 10 & 10 & 10 & - & 2.50 & 62.00 \\
\hline [39] & Isolation stage shifting & 2.08 & - & - & 17 & 3.90 & - & 70.20 \\
\hline [40] & Multilayer slot line structure & 3.22 & 10 & 10 & 10 & 5.00 & 2.00 & 105.30 \\
\hline$[41]$ & Hybrid Wilkinson and Gysel structure & 1.78 & 16 & 17 & 20 & 4.40 & 1.70 & 56.00 \\
\hline$[42]$ & LC ladder & 3.08 & 18 & 17 & 18 & 3.90 & - & 102.00 \\
\hline$[43]$ & $\begin{array}{l}\text { Port matching using three coupled-line, } \\
\text { one T-line and one isolation resistor }\end{array}$ & 2.00 & 15 & 17 & 15 & 3.20 & 0.50 & 66.67 \\
\hline$[44]$ & $\begin{array}{l}\text { Quasi-coupled line with one open stub } \\
\text { and two shorted stubs }\end{array}$ & 3.19 & 15 & 15 & 15 & 3.66 & 6.80 & 104.50 \\
\hline$[45]$ & Transversal filters with RLC network & 2.57 & 15 & 15 & 17 & - & 1.60 & 87.80 \\
\hline$[46]$ & Four T-lines, two stubs \& five resistors & 3.42 & 17.8 & 20 & 19.8 & 4.00 & - & 109.50 \\
\hline [47] & Port-to-Port isolation structure & 2.28 & 10 & 10 & 17.5 & 3.70 & 1.50 & 78.00 \\
\hline$[48]$ & $\begin{array}{l}\text { Synthesis theory and optimization } \\
\text { algorithm }\end{array}$ & 1.92 & 21.1 & 19.2 & 18.5 & 3.10 & 1.20 & 63.00 \\
\hline \multirow{2}{*}{$\begin{array}{l}\text { This } \\
\text { Work }\end{array}$} & \multirow{2}{*}{$\begin{array}{l}\text { Three Coupled T-Lines \& three isolation } \\
\text { resistors }\end{array}$} & 3.45 & 16.4 & 15 & 22 & 3.30 & 0.017 & 110.11 \\
\hline & & 5.78 & 15.9 & 12 & 10 & 3.50 & 0.021 & 141.00 \\
\hline
\end{tabular}




\section{Conclusions}

A completely new equations-based design approach for a three-section WPD has been discussed in this paper. The methodology started with deriving the required equations for the coupled transmission lines and then utilized the dual-band design technique to arrive at a robust design for a wide-band performance. The design procedure has been outlined through a compact flowchart which is followed to demonstrate some examples highlighting the capabilities of the proposed technique. Afterward, the fabricated prototype shows good agreement with the simulated data from the measurement results and substantiates the theoretical aspect. The biggest challenge of this design was to incorporate the junction discontinuities due to the use of coupled line with different widths, which needed an EM optimization. Nonetheless, the presented design equations will be the ideal choice for a computer-aided design of a miniaturized wideband WPD consisting of microstrip coupled-line.

Author Contributions: Conceptualization, M.A.M.; methodology, A.I.O.; software, A.I.O., R.I.; validation, M.A.M., A.I.O.; formal analysis, A.I.O.; investigation, A.I.O., R.I.; resources, M.A.M., C.Z., P.S.; data curation, A.I.O.; writing—original draft preparation, M.A.M., A.I.O.; writing-review and editing, M.A.M., C.Z., P.S.; visualization, A.I.O.; supervision, M.A.M., C.Z., P.S. All authors have read and agreed to the published version of the manuscript.

Funding: This research received no external funding.

Institutional Review Board Statement: Not applicable.

Informed Consent Statement: Not applicable.

Data Availability Statement: Not applicable.

Acknowledgments: Mohammad Maktoomi and Christine Zakzewski would like to acknowledge the support from the Dean of the College of Arts and Sciences, Michelle Maldonado, the department of Physics and Engineering chairperson, W. Andrew Berger; Cadence for their AWRDE tool; and Rogers Corp. for the laminate samples.

Conflicts of Interest: The authors declare no conflict of interest.

\section{References}

1. Pozar, D.M. Microwave Engineering, 4th ed.; John Wiley \& Sons, Inc.: Hoboken, NJ, USA, 2012.

2. Wilkinson, E.J. An N-way hybrid power divider. IEEE Trans. Microw. Theory Tech. 1960, 8, 116-118. [CrossRef]

3. Cohn, S.B. A class of broadband three-port TEM-mode hybrids. IEEE Trans. Microw. Theory Tech. 1968, 16, 110-116. [CrossRef]

4. Oraizi, H.; Sharifi, A.-R. Design and optimization of broadband asymmetrical multisection wilkinson power divider. IEEE Trans. Microw. Theory Tech. 2006, 54, 2220-2231. [CrossRef]

5. Honari, M.; Mirzavand, L.; Mirzavand, R.; Abdipour, A.; Mousavi, P. Theoretical design of broadband multisection Wilkinson power dividers with arbitrary power split ratio. IEEE Trans. Compon. Packag. Manuf. Technol. 2016, 6, 605-612. [CrossRef]

6. Ehsan, N.; Vanhille, K.; Rondineau, S.; Cullens, E.D.; Popović, Z.B. Broadband micro-coaxial Wilkinson dividers. IEEE Trans. Microw. Theory Tech. 2009, 57, 2783-2789. [CrossRef]

7. Lim, J.-S.; Park, U.-H.; Oh, S.; Koo, J.-J.; Jeong, Y.-C.; Ahn, D. A 800- to 3200-MHz wideband CPW balun using multistage Wilkinson structure. In Proceedings of the 2006 IEEE MTT-S International Microwave Symposium Digest, San Francisco, CA, USA, 11-16 June 2006; pp. 1141-1144.

8. Wentzel, A.; Subramanian, V.; Sayed, A.; Boeck, G. Novel broadband Wilkinson power combiner. In Proceedings of the 2006 European Microwave Conference, Manchester, UK, 10-15 September 2006; pp. 212-215.

9. Chiu, L.; Yum, T.Y.; Xue, X.; Chan, C.H. A wideband compact parallel-strip 180 Wilkinson power divider for push-pull circuitries. IEEE Microw. Wireless Compon. Lett. 2006, 16, 49-51. [CrossRef]

10. Wong, S.W.; Zhu, L. Ultra-wideband power dividers with good isolation and sharp roll-off skirt. IEEE Microw. Wireless Compon. Lett. 2008, 18, 518-520. [CrossRef]

11. Lan, X.; Chang-Chien, P.; Fong, F.; Eaves, D.; Zeng, X.; Kintis, M. Ultra-wideband power divider using multi-wafer packaging technology. IEEE Microw. Wireless Compon. Lett. 2011, 21, 46-48. [CrossRef]

12. Sun, Y.; Freundorfer, A.P. Broadband folded Wilkinson power splitter. IEEE Microw. Wireless Compon. Lett. 2004, 14, 295-297. [CrossRef] 
13. Chen, C.-C.; Cin, J.-J.; Wang, S.-H.; Lin, C.-C.; Tzuang, C.-K.C. A novel miniaturized wideband Wilkinson power divider employing two-dimensional transmission line. In Proceedings of the 2008 IEEE International Symposium on VLSI Design, Automation and Test (VLSI-DAT), Hsinchu, Taiwan, 23-25 April 2008; pp. 212-215.

14. Chiang, M.-J.; Wu, H.-S.; Tzuang, C.-K.C. A -band CMOS Wilkinson power divider using synthetic quasi-TEM transmission lines. IEEE Microw. Wireless Compon. Lett. 2007, 17, 837-839. [CrossRef]

15. Park, M.-J. Dual-band Wilkinson divider with coupled output port extensions. IEEE Trans. Microw. Theory Tech. 2009, 57, 2232-2237. [CrossRef]

16. Wu, Y.; Liu, Y.; Xue, Q. An analytical approach for a novel coupled-line dual-band Wilkinson power divider. IEEE Trans. Microw. Theory Tech. 2011, 59, 286-294. [CrossRef]

17. Chang, T.-J.; Tsao, Y.-F.; Huang, T.-J.; Hsu, H.-T. Bandwidth Improvement of Conventional Dual-Band Power Divider Using Physical Port Separation Structure. Electronics 2020, 9, 2192. [CrossRef]

18. Vincenti Gatti, R.; Rossi, R.; Dionigi, M. Wideband Rectangular Waveguide to Substrate Integrated Waveguide (SIW) E-Plane T-Junction. Electronics 2021, 10, 264. [CrossRef]

19. Kawai, T.; Yamasaki, J.; Kokubo, Y.; Ohta, I. A design method of dual-frequency Wilkinson power divider. In Proceedings of the 2006 Asia-Pacific Microwave Conference, Yokohama, Japan, 12-15 December 2006; pp. 913-916.

20. Wang, X.; Sakagami, I. Generalized dual-frequency Wilkinson power dividers with a series/parallel RLC circuit. In Proceedings of the 2011 IEEE MTT-S International Microwave Symposium, Baltimore, MD, USA, 5-10 June 2011; pp. 1-4.

21. Wu, Y.; Liu, Y.; Li, S. Unequal dual-frequency Wilkinson power divider including series resistor-inductor-capacitor isolation structure. IET Microw. Antennas Propag. 2009, 3, 1079-1085. [CrossRef]

22. Wu, Y.; Liu, Y.; Zhang, Y.; Gao, J.; Zhou, H. A dual band unequal Wilkinson power divider without reactive components. IEEE Trans. Microw. Theory Tech. 2009, 57, 216-222.

23. Genc, A.; Baktur, R. Dual-and triple-band Wilkinson power dividers based on composite right-and left-handed transmission lines. IEEE Trans. Compon. Packag. Manuf. Tech. 2011, 1, 327-334. [CrossRef]

24. Kao, J.-C.; Tsai, Z.-M.; Lin, K.-Y.; Wang, H. A modified Wilkinson power divider with isolation bandwidth improvement. IEEE Trans. Microw. Theory Tech. 2012, 60, 2768-2780. [CrossRef]

25. Wang, Y.; Zhang, Y.X.; Liu, X.F.; Lee, C.J. A compact bandpass Wilkinson power divider with ultra-wide band harmonic suppression. IEEE Microw. Wirel. Compon. Lett. 2017, 27, 888-890. [CrossRef]

26. Chen, M.T.; Tang, C.W. Design of the filtering power divider with a wide passband and stopband. IEEE Microw. Wirel. Compon. Lett. 2018, 28, 570-572. [CrossRef]

27. Tas, V.; Atalar, A. An optimized isolation network for the Wilkinson divider. IEEE Trans. Microw. Theory Tech. 2014, 62, 3393-3402. [CrossRef]

28. Cheng, P.; Wang, Q.; Li, W.; Jia, Y.; Liu, Z.; Feng, C.; Jiang, L.; Xiao, H.; Wang, X. A Broadband Asymmetrical GaN MMIC Doherty Power Amplifier with Compact Size for 5G Communications. Electronics 2021, 10, 311. [CrossRef]

29. Nouri, M.E.; Roshani, S.; Mozaffari, M.H.; Nosratpour, A. Design of high-efficiency compact Doherty power amplifier with harmonics suppression and wide operation frequency band. AEU Int. J. Electron. C. 2020, 118, 153168. [CrossRef]

30. Hookari, M.; Roshani, S.; Roshani, S. High-efficiency balanced power amplifier using miniaturized harmonics suppressed coupler. Int. J. RF Microw. Comput. -Aided Eng. 2020, 30, e22252. [CrossRef]

31. Tseng, C.H.; Chang, C.L. Improvement of return loss bandwidth of balanced amplifier using metamaterial-based quadrature power splitters. IEEE Microw. Wireless Compon. Lett. 2008, 18, 269-271. [CrossRef]

32. Islam, R.; Maktoomi, M.H.; Gu, Y.; Arigong, B. Concurrent Dual-Band Microstrip Line Hilbert Transformer for Spectrum Aggregation Real-Time Analog Signal Processing. In Proceedings of the 2020 IEEE/MTT-S International Microwave Symposium (IMS), Los Angeles, CA, USA, 4-6 August 2020; pp. 900-903.

33. Islam, R.; Maktoomi, M.H.; Ren, H.; Arigong, B. Spectrum Aggregation Dual-Band RealTime RF/Microwave Analog Signal Processing from Microstrip Line High-Frequency Hilbert Transformer. IEEE Trans. Microw. Theory Tech. 2021, 1, 1. [CrossRef]

34. Boutayeb, H.; Watson, P.R.; Lu, W.; Wu, T. Beam switching dual polarized antenna array with reconfigurable radial waveguide power dividers. IEEE Trans. Antenn Propag. 2016, 65, 1807-1814. [CrossRef]

35. Gao, S.S.; Sun, S.; Xiao, S. A novel wideband bandpass power divider with harmonic-suppressed ring resonator. IEEE Microw. Wireless Compon. Lett. 2013, 23, 119-121. [CrossRef]

36. Zhang, B.; Yu, C.; Liu, Y. Compact power divider with bandpass response and improved out-of-band rejection. J. Electromagn. Waves Appl. 2016, 30, 1124-1132. [CrossRef]

37. Maktoomi, M.A.; Akbarpour, M.; Hashmi, M.S.; Ghannouchi, F.M. On the dual frequency impedance/admittance characteristic of multi-section commensurate transmission-line. IEEE Trans. on Circuits Syst. II Exp. Briefs 2017, 64, 665-669. [CrossRef]

38. Kim, S.-H.; Yoon, J.-H.; Kim, Y.; Yoon, Y.-C. A modified Wilkinson divider using zero-degree phase shifting composite right/lefthanded transmission line. In Proceedings of the 2010 IEEE MTT-S International Microwave Symposium, Anaheim, CA, USA, 23-28 May 2010; pp. 1556-1559.

39. Trantanella, C.J. A novel power divider with enhanced physical and electrical port isolation. In Proceedings of the 2010 IEEE MTT-S International Microwave Symposium, Anaheim, CA, USA, 23-28 May 2010; pp. 129-132.

40. Song, K.; Xue, Q. Novel ultra-wideband (UWB) multilayer slotline power divider with bandpass response. IEEE Microw. Wireless Compon. Lett. 2010, 20, 13-15. [CrossRef] 
41. Liu, Y.; Sun, S.; Yu, X.; Wu, Y.; Liu, Y. Design of a wideband filtering power divider with good in-band and out-of-band isolations. Int. J. RF Microw. Comput. Aid Eng. 2019, 29, e21728. [CrossRef]

42. Okada, Y.; Kawai, T.; Enokihara, A. Wideband lumped-element Wilkinson power dividers using LC-ladder circuits. In Proceedings of the 2015 European Microwave Conference (EuMC), Paris, France, 7-10 September 2015; pp. 115-118.

43. Maktoomi, M.A.; Hashmi, M.S.; Ghannouchi, F.M. Theory and design of a novel wideband DC isolated Wilkinson power divider. IEEE Microw. Wireless Compon. Lett. 2016, 26, 586-588. [CrossRef]

44. Tang, C.-W.; Chen, J.-T. A design of 3-dB wideband microstrip power divider with an ultra-wide isolated frequency band. IEEE Trans. Microw. Theory Tech. 2016, 64, 1806-1811. [CrossRef]

45. Jiao, L.; Wu, Y.; Liu, Y.; Xue, Q.; Ghassemlooy, Z. Wideband filtering power divider with embedded transversal signal-interference sections. IEEE Microw. Wireless Compon. Lett. 2017, 27, 1068-1070. [CrossRef]

46. Wang, X.; Ma, Z.; Xie, T.; Ohira, M.; Chen, C.-P.; Lu, G. Synthesis Theory of Ultra-Wideband Bandpass Transformer and its Wilkinson Power Divider Application with Perfect in-Band Reflection/Isolation. IEEE Trans. Microw. Theory Tech. 2019, 67, 3377-3390. [CrossRef]

47. Liu, Y.; Zhu, L.; Sun, S. Proposal and Design of a Power Divider with Wideband Power Division and Port-to-Port Isolation: A New Topology. IEEE Trans. Microw. Theory Tech. 2020, 68, 1431-1438. [CrossRef]

48. Bao, C.; Wang, X.; Ma, Z.; Chen, C.-P.; Lu, G. An Optimization Algorithm in Ultrawideband Bandpass Wilkinson Power Divider for Controllable Equal-Ripple Level. IEEE Microw. Wireless Compon. Lett. 2020, 30, 861-864. [CrossRef] 